\title{
Strategies to improve anxiety and depression in patients with COPD: a mental health perspective
}

This article was published in the following Dove Press journal:

Neuropsychiatric Disease and Treatment

9 February 2016

Number of times this article has been viewed

\author{
Athanasios Tselebis' \\ Argyro Pachi' \\ loannis llias ${ }^{2}$ \\ Epaminondas Kosmas ${ }^{3}$ \\ Dionisios Bratis \\ Georgios Moussas' \\ Nikolaos Tzanakis ${ }^{4,5}$ \\ 'Psychiatric Department, "Sotiria" \\ General Hospital of Chest Disease, \\ Athens, Greece; ${ }^{2}$ Endocrinology \\ Department, "Elena Venizelou" \\ Hospital, Athens, Greece; ${ }^{3 P u l m o n a r y}$ \\ Department, "Metropolitan" \\ General Hospital, Athens, Greece; \\ ${ }^{4}$ Department of Thoracic Medicine, \\ ${ }^{5}$ Social Medicine, Laboratory of \\ Epidemiology, University of Crete \\ Medical School, Heraklion, Greece
}

Video abstract

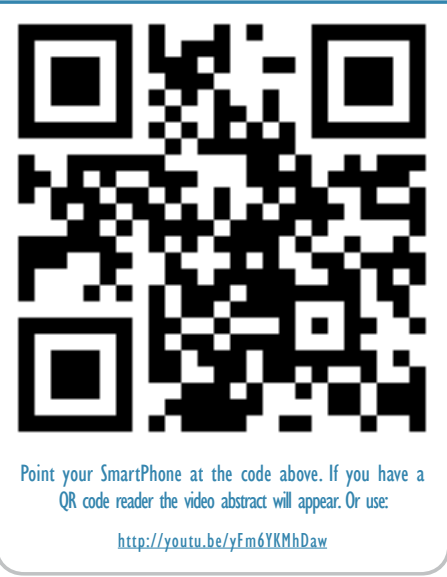

Correspondence: Athanasios Tselebis Psychiatric Department, "Sotiria" General Hospital of Chest Disease, Mesogeion 152, 11527 Athens, Greece Email atselebis@yahoo.gr

\begin{abstract}
Chronic obstructive pulmonary disease (COPD) is a chronic inflammatory lung disease characterized by progressive and only partially reversible symptoms. Worldwide, the incidence of COPD presents a disturbing continuous increase. Anxiety and depression are remarkably common in COPD patients, but the evidence about optimal approaches for managing psychological comorbidities in COPD remains unclear and largely speculative. Pharmacological treatment based on selective serotonin reuptake inhibitors has almost replaced tricyclic antidepressants. The main psychological intervention is cognitive behavioral therapy. Of particular interest are pulmonary rehabilitation programs, which can reduce anxiety and depressive symptoms in these patients. Although the literature on treating anxiety and depression in patients with COPD is limited, we believe that it points to the implementation of personalized strategies to address their psychopathological comorbidities.
\end{abstract}

Keywords: COPD, anxiety, depression, pharmacological treatment, psychotherapy

\section{Introduction}

The Global Initiative for Chronic Obstructive Lung Disease (GOLD) defines chronic obstructive pulmonary disease (COPD) as a disease state characterized by exposure to noxious agents resulting in airflow limitation that is not fully reversible, causing shortness of breath and significant systemic effects. ${ }^{1}$ This definition covers a spectrum of respiratory diseases, and includes both the clinical diagnosis of chronic bronchitis and the pathological diagnosis of emphysema. ${ }^{2}$ In clinical practice, COPD is defined by characteristically diminished air flow in lung function tests. Spirometry is required to make the diagnosis and staging in this clinical context; ${ }^{3}$ the presence of a postbronchodilator forced expiratory volume in 1 second/forced vital capacity $\left(\mathrm{FEV}_{1} / \mathrm{FVC}\right)<0.70$ confirms the presence of persistent airflow limitation and thus of COPD. Unlike asthma, the limitation is practically irreversible and usually worsens gradually over time. ${ }^{4}$ This worsening is causally related to an abnormal inflammatory response of the lungs to inhaled harmful particles or gases, attributed - usually - to smoking. ${ }^{5}$

COPD is a leading cause of morbidity and mortality worldwide and results in an economic and social burden that is both substantial and increasing. ${ }^{6} \mathrm{COPD}$ prevalence, morbidity, and mortality vary across countries and across different groups within countries. The Global Burden of Disease Study estimated that COPD will become the fourth leading cause of death and the seventh leading cause of disability-adjusted life year(s) lost worldwide by $2030 .^{7}$ The death rate associated with COPD has doubled in the past 30 years,${ }^{8}$ implying that the health-care system failed to address the problem. ${ }^{9}$

Comorbidity studies ${ }^{10-12}$ from Western and developing countries, inpatient and outpatient population, and younger and elderly patients reveal a substantial overrepresentation of anxiety and depression in COPD, from significant symptoms to full 
diagnostic mental disorders, ${ }^{13}$ according to Diagnostic and Statistical Manual of Mental Disorders-4th edition (DSM-IV) and International Classification of Diseases, 10th Revision (ICD-10) taxonomic systems. Prevalence rates of both anxiety and depression in patients with COPD vary widely depending on the population surveyed and the measurement tools. Also, the overlap between symptoms of COPD disease and symptoms of anxiety and depression may contribute to the variations in prevalence figures, especially because questionnaires designed to screen for anxiety and depression include a large number of somatic complaints (poor sleeping pattern, anorexia, breathlessness, and fatigue). ${ }^{14}$

Anxiety in COPD patients is often associated with clinical depression, and studies indicate that depressed COPD patients have a seven-fold risk to suffer from comorbid clinical anxiety compared to nondepressed COPD patients. ${ }^{11,15}$ There is an overlap in existing symptomatology between the two disorders, with fatigue, weight changes, sleep disturbance, agitation, irritability, and difficulty in concentrating appearing as common symptoms. ${ }^{16}$

In outpatients with COPD, studies indicate rates of depression varying from $7 \%$ to $80 \%$ and that of anxiety from $2 \%$ to $80 \%{ }^{14-26}$ Prevalence of generalized anxiety disorder (GAD) ranges from $10 \%$ to $33 \%^{27,28}$ and of panic attacks or panic disorder (PD) from $8 \%$ to $67 \%{ }^{28}$ In stable COPD, the prevalence of clinical depression ranges from $10 \%$ to $42 \%$ and that of anxiety between $10 \%$ and $19 \% .{ }^{29}$ In a systematic review $^{30}$ that focused on patients with severe COPD disease, the prevalence of depression ranged from $37 \%$ to $71 \%$ and that of anxiety from $50 \%$ to $75 \%$, figures comparable to or higher than prevalence rates in other advanced diseases such as cancer, HIV, heart disease, and renal disease.

Comorbid psychological impairments in COPD patients predict increased functional impairment, ${ }^{15,31}$ disability ${ }^{17}$ and morbidity, ${ }^{32,33}$ lower quality of life, ${ }^{34,35}$ and decreased adherence to the treatment. ${ }^{36,37}$ A systematic review and a metaanalysis have shown that depression and anxiety increase the risk of hospitalization for COPD patients..$^{9,38}$ Also, patients with comorbidity spend twice as long time in hospitals and have increased mortality rates. ${ }^{39-42}$

Accordingly, recent consensus statements and guidelines on optimal care for COPD patients emphasize the need for assessment and adequate treatment of persisting anxiety and depressive symptoms in these patients. Despite the high prevalence and considerable negative impact of coexisting psychopathology in COPD, the evidence about optimal approaches for managing depression and anxiety remains unclear and largely speculative.
The objectives of this paper are to provide an overview of the prevalence, impact, and pathophysiology associated with anxiety and depression in patients with COPD and to review studies on pharmacological and nonpharmacological interventions, in an effort to highlight current knowledge and identify needs for future research.

\section{Anxiety in patients with COPD}

Anxiety disorder is a generalized term for a variety of abnormal and pathological fear and anxiety states, including GAD, PD, agoraphobia, obsessive-compulsive disorder, phobic disorders, and traumatic stress disorders. Anxiety disorders are defined using established diagnostic criteria, eg, current versions of $D S M^{43}$ or $\mathrm{ICD}^{44}$ criteria, while anxiety symptoms are assessed using formal psychological instruments, eg, Hamilton Anxiety Rating Scale, ${ }^{45}$ Beck Anxiety Inventory, ${ }^{46}$ and State-Trait Anxiety Inventory. ${ }^{47}$ GAD and PD occur at a higher rate in patients with COPD compared with the general population. ${ }^{48}$ Symptoms of anxiety are manifested in a variety of ways, including physiological signs of arousal, such as tachycardia, sweating, and dyspnea. Anxiety in patients with COPD is intimately linked with the fear of acute dyspnea attacks and essentially with the sense of suffocation and the fear of death. ${ }^{49-51}$

The prevalence of anxiety-related disorders in COPD is associated with reduced functional ability and rehospitalizations. ${ }^{52}$ Common mechanisms for explaining this high association include factors related to smoking and dyspnea. Smoking is widely acknowledged as the most important environmental risk factor for the development of COPD, ${ }^{53}$ and high levels of anxiety have been identified as a risk factor for the initiation of smoking. ${ }^{54,55}$ Thus people who develop COPD as a consequence of smoking probably experienced higher levels of anxiety than the general population prior to developing the disease, and moreover, these individuals may have a greater tendency to addiction since nicotine withdrawal is associated with greater symptoms of anxiety. ${ }^{56-58}$

Evidence also suggests pathophysiologic relationships among dyspnea, hyperventilation, and anxiety. ${ }^{49}$ Physiological research has demonstrated both that respiratory rate is increased by anxiety and that the resulting rapid, shallow breathing pattern markedly worsens dyspnea in COPD. ${ }^{59,60}$ The key common physiological factors in COPD are increased ventilatory load, reduced ventilatory capacity, and increased neural respiratory drive, hyperinflation, and neuromechanical dissociation, leading to an efferent-afferent mismatch, which is fundamental to the origin of dyspnea. ${ }^{61}$ When the sense of heightened effort increases beyond 
a certain threshold and/or the dissociation between neural drive and the mechanical response reaches a critical level (which likely varies between individuals), it will generate a strong emotional reaction (ie, fear, distress, and anxiety) in the individual, which in turn will precipitate conditioned behavioral (avoidance) responses..$^{62,63}$ These strategies help to attenuate neuromechanical dissociation and to allay anxiety. In some patients these compensations are not possible, and the affective response can quickly escalate to overt panic and overwhelming feelings of lack of control. ${ }^{64}$ Extreme fear and foreboding will, in turn, trigger patterned ventilatory and circulatory responses (via sympathetic nervous system activation) that can further amplify respiratory discomfort. The vicious cycle of breathlessness and anxiety conceptualized as "dyspnea-anxiety-dyspnea cycle" relationship suggests patients' emotional response to breathlessness exacerbates their perception of breathlessness. ${ }^{65}$ This cycle can be illustrated by the cognitive behavioral model of dyspnea, hyperventilation, and anxiety. ${ }^{49}$ This positive feedback cycle states that individuals may misinterpret physical sensations such as dyspnea, leading to anxiety, further autonomic arousal, and increased dyspnea. ${ }^{66,67}$

Other theories proposed to explain the overlap of anxiety and panic attack symptoms with COPD are the hyperventilation model and the carbon dioxide hypersensitivity model. Hyperventilation in excess of metabolic need leads to a decrease in $\mathrm{pCO}_{2}$, causing a respiratory alkalosis that leads to vasoconstriction and typical panic symptoms such as light-headedness, numbness, tingling sensations, and shortness of breath, in healthy individuals. ${ }^{60}$ In COPD patients, increased frequency of breathing predisposes to dynamic hyperinflation, due to the slow time constant for lung deflation. Hyperinflation increases the elastic load, work, and effort of breathing, reduces inspiratory reserve capacities, and exacerbates dyspnea ${ }^{68}$ In patients with severe COPD, chronic hypoventilation induces hypercapnia. ${ }^{60} \mathrm{An}$ increase in $\mathrm{pCO}_{2}$ levels has been shown to activate medullary chemoreceptors, which elicits a panic response by activating noradrenergic neurons in the locus ceruleus. ${ }^{95}$ Lactate acid, formed because of hypoxia is also linked to panic attacks, and evidence suggests that patients with both COPD and anxiety are hypersensitive to lactic acid and hyperventilation. ${ }^{49}$ In other words, the pathogenesis of panic may be related to respiratory physiology by several mechanisms: the anxiogenic effects of hyperventilation, the catastrophic misinterpretation of respiratory symptoms, and/or a neurobiologic sensitivity to $\mathrm{CO}_{2}$, lactate, or other signals of suffocation. Consequently, there is a reason to believe that chronic pulmonary disease constitutes a risk factor for the development of panic anxiety related to repeated experiences with dyspnea and life threatening exacerbations of pulmonary dysfunction, repeated episodes of hypercapnia or hyperventilation, the use of anxiogenic medications, and the stress of coping with chronic disease. ${ }^{69}$

Anxiety symptoms may distract patients from selfmanagement of disease exacerbations. ${ }^{70}$ Even a low intensity dyspnea attack is able to trigger panic anxiety which in turn heightens the sensation of dyspnea and sense of suffocation, thus creating a vicious cycle that forces many patients to restrict their daily activities. ${ }^{70-72}$ Patients with COPD usually describe their understanding of acute dyspnea as an experience inextricably related to anxiety and emotional functioning. As a result, this comorbidity leads to significant decrease in functional capacity, including phobic avoidance of activity because of anticipatory anxiety, further deconditioning, and misuse of anxiogenic medications ${ }^{73}$ ( $\beta_{2}$ agonists, theophylline, and oral corticosteroids).

Recognition of the presence of this pathophysiological mechanism provides a more comprehensive assessment of the additional functional impairment experienced by the patient even if biological parameters and laboratory results are insufficient to justify the compromised ability to perform physical functions..$^{15,21,52}$ Sense of loss of control over the disease itself and loss of mastery ${ }^{74,75}$ over their ability to engage in personal and social activities engenders frustration and anxious feelings.

It is important to note that dyspnea at rest or on exertion does not correlate with the magnitude of anxiety-related symptoms, and furthermore, the magnitude of decrease in dyspnea with pharmacotherapy or exercise training is not associated with the reduction in anxiety-related symptoms, this indicates that there are other factors contributing to this relationship. ${ }^{76}$ Additionally, although patients with panic report more catastrophic misinterpretations of bodily symptoms, they do not differ from patients without panic on measures of physical functioning, disease severity, shortness of breath, or psychological distress. Thus, it has been suggested that panic symptoms may reflect a cognitive interpretation of pulmonary symptoms rather than objective pulmonary status. ${ }^{66}$

Studies indicate that anxiety and depression were not correlated with COPD severity ${ }^{77}$ (as determined by FEV ${ }_{1} \%$ of predicted), and it is reported that dyspnea ratings were influenced by anxiety and depressive symptoms, whereas the physiological state scarcely influenced the anxiety and depressive symptomatology. ${ }^{78}$ A possible explanation is that 
patients construe disease seriousness subjectively, which contributes to the development of the levels of anxiety and depressive symptoms. ${ }^{14}$

\section{Depression in patients with COPD}

Today, the ICD- $10^{44}$ and $D S M-V^{79}$ criteria for depression are the most common diagnostic tools. Different subtypes of depression have been defined, and the clinical course of depression is acknowledged to be variable with patients moving in and out the diagnostic subtypes over time. When it comes to depression in patients with severe somatic illness, the validity of DSM criteria may to a certain degree be questioned because it is difficult to decide when somatic symptoms are secondary to depression, or when they are secondary to somatic illness. ${ }^{80}$ Severity of depression is determined by the number and level of symptoms, as well as the degree of functional impairment. Patients with COPD may have a spectrum of symptom severity ranging from short-term depressive symptoms or adjustment disorder with depressed mood to dysthymia up to major depression.

In a cluster of studies that have compared depressive disorders across various chronic illnesses, COPD patients suffer from depression with greater frequency and greater chronicity of mood symptoms. ${ }^{81-84}$ Also, few studies ${ }^{10,52}$ have reported that approximately two-thirds of COPD patients with depression have moderate-to-severe depression, and in one study, ${ }^{85}$ it was reported that approximately one-fourth of COPD patients had unrecognized subclinical depression.

Depression in patients with COPD is often marked by feelings of hopelessness and pessimism, reduced sleep, decreased appetite, increased lethargy, difficulties in concentration, social withdrawal, impairment in functional abilities and performing activities of daily living, poorer self-reported health, impaired self-management of disease exacerbations, and poor health behaviors. ${ }^{52,70,86-91}$ The correlation between depressed mood and disease severity is modest $;{ }^{21}$ but depression symptoms are important correlates of perceived selfreported physical disability and poorer quality of life..$^{85}$ Guilty feelings stemming from the sense of burden patients impose to their environment, in combination with the responsibility they might think they have for the occurrence of the disease, especially concerning ex-smokers, aggravates depressive symptomatology. ${ }^{92}$

According to studies, clinically significant levels of depression and anxiety were more prevalent in younger COPD patients, irrespective of clinical severity of COPD, perhaps because younger patients may find it difficult to come to terms with enforced changes in lifestyle, with this leading to increased psychological morbidity. ${ }^{93}$

Recent studies suggest that depression in patients with COPD is a heterogeneous entity with multiple contributing etiologies including genetic predisposition, environmental losses and stressors, and direct damage to the brain mediated by the physiologic effects of chronic respiratory disease. ${ }^{94}$

The genetic vulnerability plays a role in the eventual development of COPD in that adolescents and young adults who are depressed or have a history of depression are more likely to progress in their use of and dependence on nicotine. ${ }^{54,55,96}$ Smoking, COPD, and depression form a dynamic model of circular causality, with depression playing a role in the initiation and maintenance of smoking, smoking leading to the development of COPD, and COPD in turn contributing to the genesis of depression. ${ }^{94}$

Evidence suggests that the appearance of major depression or depressive symptomatology in patients suffering from a chronic disabling general medical condition is common and justified as a "reaction" to the losses imposed by the illness in both symbolic order and real grounds. ${ }^{97}$ These losses may include functional impacts ${ }^{98}$ such as inability to carry out prior occupational activities, shifted roles within the family, and social constellation, but also an insult to self-image that patients experience with the change in their general physical condition and somatic functioning. ${ }^{94}$ Losses for patients with COPD increase with the gradual deterioration of the disease. Dyspnea ${ }^{65,99}$ is the most common and disabling symptom experienced by COPD patients and is inextricably associated with feelings of despair, helplessness, and alienation, resulting in the apparent loss of interest for life and other people.

By the very nature of the disease process, COPD is associated with chronic, if often subclinical, hypoxemia. Low arterial oxygen saturation has been shown to be associated with periventricular white matter lesions, ${ }^{100}$ which are also present in elderly patients with depression. ${ }^{101}$ Several authors have investigated the relationship between chronic hypoxemia and neuropsychological function, and the consequences of chronic hypoxemia include both impaired cognitive function and depression. ${ }^{102,103}$ Most studies of hypoxemia and depression arise from the sleep apnea literature where one of the primary identified sequelae of recurrent nocturnal hypoxemia is depressed mood. ${ }^{104}$

Both depression and COPD have been associated with processes that jeopardize the microvasculature of the brain, ${ }^{105,106}$ and there is evidence for systemic inflammation and elevated biomarkers of oxidative damage. ${ }^{107}$ Although 
there are difficulties in quantification of inflammatory biomarkers, sTNFR-1 has shown a strong association with rates of depression in COPD patients. ${ }^{108}$ In the absence of prior comorbidity, systemic inflammation in COPD may result in depression and IL-6 appears to play a particularly important role in humans and in animal models of depression. ${ }^{109}$ A prospective cohort study indicated that the mean time elapsed between the diagnosis of COPD and the first episode of depression was 7.6 years. ${ }^{110}$ The long-term use of systemic corticosteroids has also been related to depression in COPD, but results are inconclusive. ${ }^{111}$

Although smoking, hypoxia, and inflammation have potential impact on the prevalence of depression in COPD, the strongest predictors of depression among patients with COPD are their severity of symptoms and reported quality of life..$^{33}$ The advantage to recognizing the interdependent relationship of these contributing factors is the corollary recognition that effective intervention in any one of them will have a cascading, positive impact on the others. Effectively targeting depression, lost functionality, or chronic hypoxemia will decrease morbidity in that dimension, and potentially in the others as well.

\section{Treatment}

Despite high prevalence rates and deleterious impact of comorbid anxiety and depression in COPD, only a limited number of studies have addressed its management, ${ }^{26}$ accounting for the absence of recommendations regarding their treatment in the updated GOLD guidelines. ${ }^{1}$ Only pulmonary rehabilitation (PR) is suggested as treatment option (evidence A), which is also available for only a small percentage of patients. ${ }^{12}$ The National Institute for Health and Care Excellence (NICE) has published clinical guidelines for the use of stepped approaches to psychological and/or pharmacological treatment of depression in people with long-term conditions. ${ }^{113}$ In recognition of the expanding knowledge and the clinical importance of this area, we attempted to summarize existing empirical evidence based on studies implementing pharmacological and nonpharmacological interventions to reduce clinical anxiety and depression in people with COPD.

\section{Method}

A literature search was conducted for studies examining the effect of anxiolytic and antidepressant medical treatment, cognitive behavioral therapy (CBT), PR, and other complex interventions on anxiety and depressive symptoms in COPD patients, using PubMed databases. Essential keywords were “chronic obstructive pulmonary disease" OR "COPD” AND "anxiety" OR "depression" to capture the target population. Intervention search terms comprised "medication" OR "pharmacological treatment" OR "SSRIs" OR "antidepressants" OR "TCAs" OR "SNRIs" OR "mirtazapine" OR "buspirone” OR "benzodiazepines” OR "psychological interventions" OR "cognitive behavioural therapy" OR “psychotherapy” OR “pulmonary rehabilitation” OR “group therapy" OR “complex interventions" OR "relaxation” OR "health education" OR "counselling" OR "behavioural interventions" OR "alternative treatments" OR "Tai Chi" OR "yoga".

\section{Eligibility criteria}

Studies for inclusion were required to be in the English language and meet participant, intervention, comparator, and outcome criteria, ${ }^{114,115}$ for studies of controlled comparative design. We also included nonrandomized studies such as clinical trials, crossover studies, observational studies, and relevant review articles and meta-analyses. Participants were adults (men and women of age $\geq 18$ years), with a confirmed diagnosis of COPD as defined by the GOLD standard, who were treated for symptoms of anxiety and depression. Mode of interventions was pharmacological and nonpharmacological, and was aimed at reducing symptoms of anxiety and depression. The primary outcomes of interest were reduction in these symptoms following the administration of these interventions. The outcome was measured by changes from baseline anxiety and depression scores to posttreatment scores, employing validated psychological assessment instruments.

\section{Quality assessment}

The quality of included controlled comparative design studies was assessed by two authors independently with respect to the Critical Appraisal Skills Program checklists for risk of bias evaluation. ${ }^{116}$ The methodological quality of full-text articles was assessed employing checklists from the Scottish Intercollegiate Guidelines Network. ${ }^{300}$

\section{Results}

Electronic database searches yielded 637 records with 438 remaining after removal of duplicates. From the initial title screenings, 253 potentially relevant articles were identified and their abstracts were subsequently reviewed. Of these, 167 were excluded as they failed to meet inclusion criteria. Seventy-two studies and 14 reviews were retrieved in full text for further assessment. 


\section{Overview and effects of pharmacological and nonpharmacological interventions on anxiety and depression in COPD}

Tables 1-4 outline the characteristics of pharmacological and nonpharmacological interventions reported in the included studies. The results column describes the effects of interventions in narratives, thus enabling comparisons across various studies.

\section{Pharmacological treatment}

Management of depression and anxiety in COPD patients starts with the correct diagnosis. Many patients suffer transitory mood symptoms during respiratory exacerbations and there is no evidence that these time-limited symptoms require specific treatment. NICE guidelines ${ }^{117}$ advise that antidepressants should not be routinely prescribed for physically ill patients with subthreshold symptoms of depression or mild-to-moderate depression. Pharmacological therapy must be considered when major depression is diagnosed to avoid its long-term effects on overall disability. ${ }^{17,118-120}$ A recent study in USA reported that less than a third of COPD patients with major depression received appropriate treatment. ${ }^{121}$ The importance of routine screening in COPD patients for depressive symptoms is considered paramount in order to initiate the most appropriate treatment (especially after acute exacerbations and when changes occur in patients' circumstances). ${ }^{122}$

All antidepressants have similar effectiveness but mainly differ based on type and severity of side effects. Based on which chemicals in the brain they affect, the main categories are tricyclic antidepressants (TCAs), tetracyclic antidepressants, monoamine oxidase inhibitors, reversible inhibitors of monoamine oxidase, selective serotonin reuptake inhibitors (SSRIs), serotonin and noradrenaline reuptake inhibitors, noradrenergic and specific serotonergic antidepressants, norepinephrine and dopamine reuptake inhibitors, and melatonergic antidepressants.

The choice of antidepressant depends on the pattern of depression, ${ }^{123}$ and it is useful to differentiate between early- and late-onset depression, ${ }^{94}$ because there is a distinct symptom profile that necessitates diverse treatment strategies. Late-onset depression or geriatric vascular depression after COPD diagnosis, caused by physiologic changes associated with COPD that have direct effect on brain's vasculature, is characterized by more cognitive dysfunction, physical disability, limited insight, and psychomotor

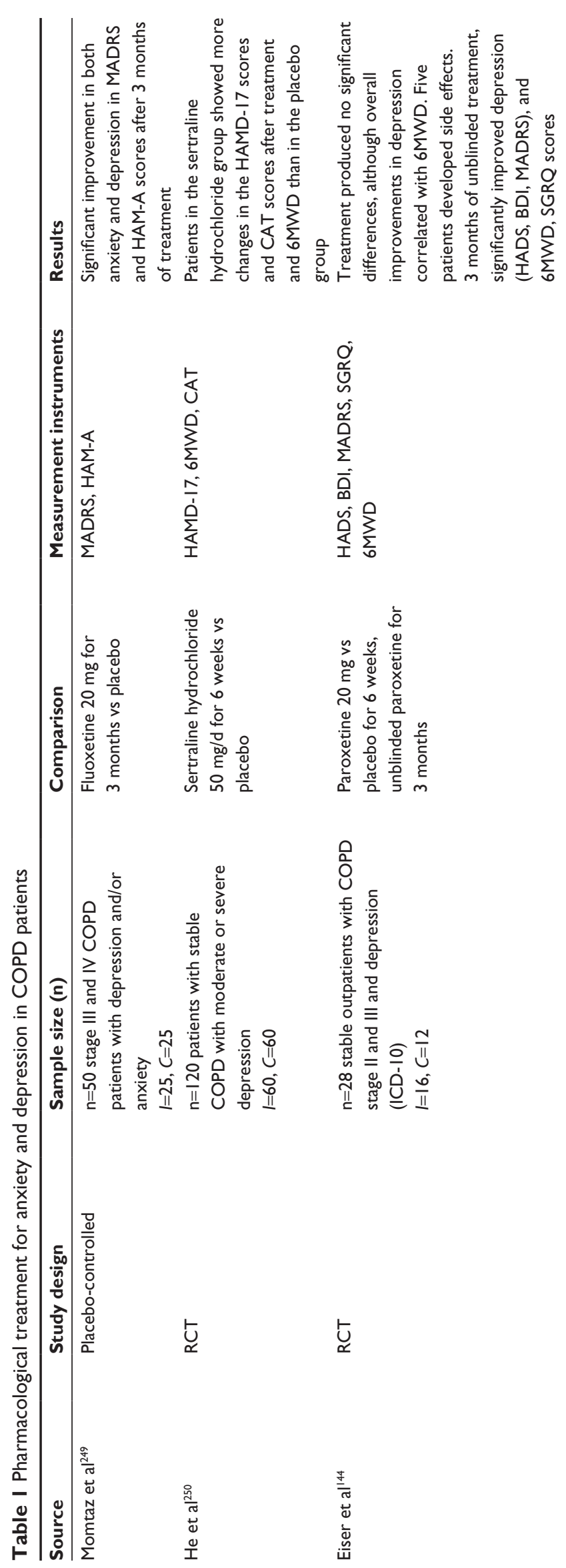



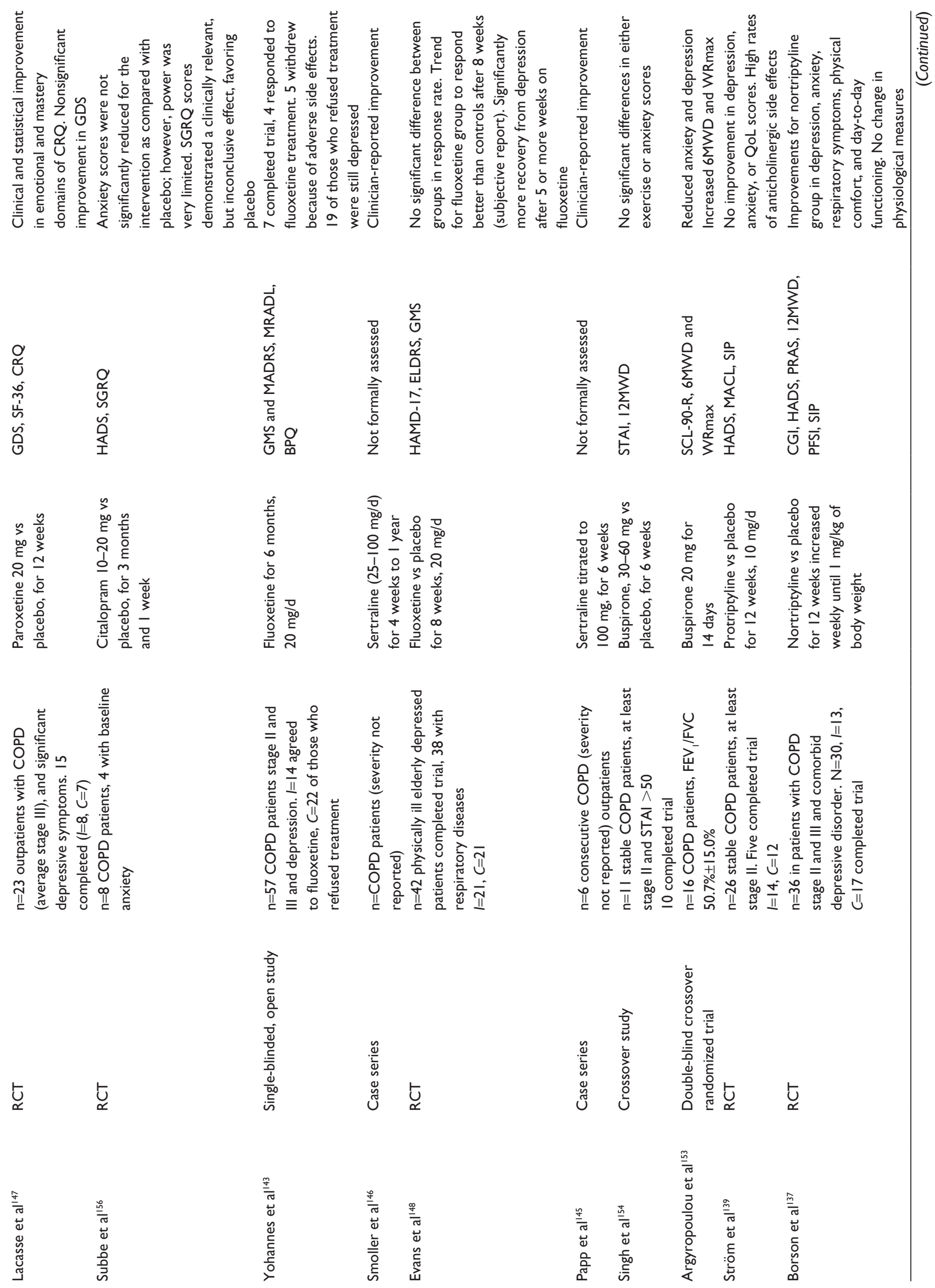


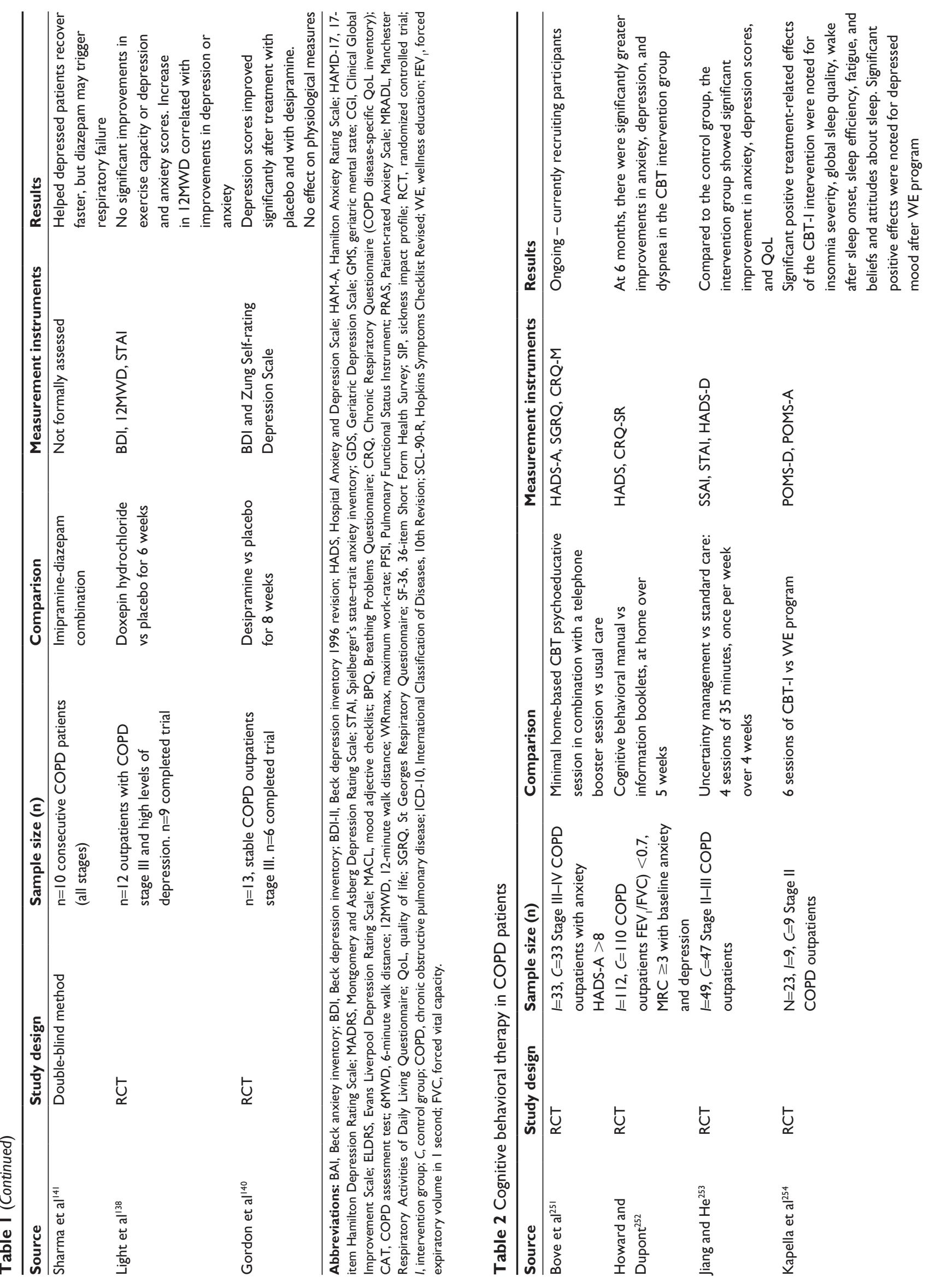



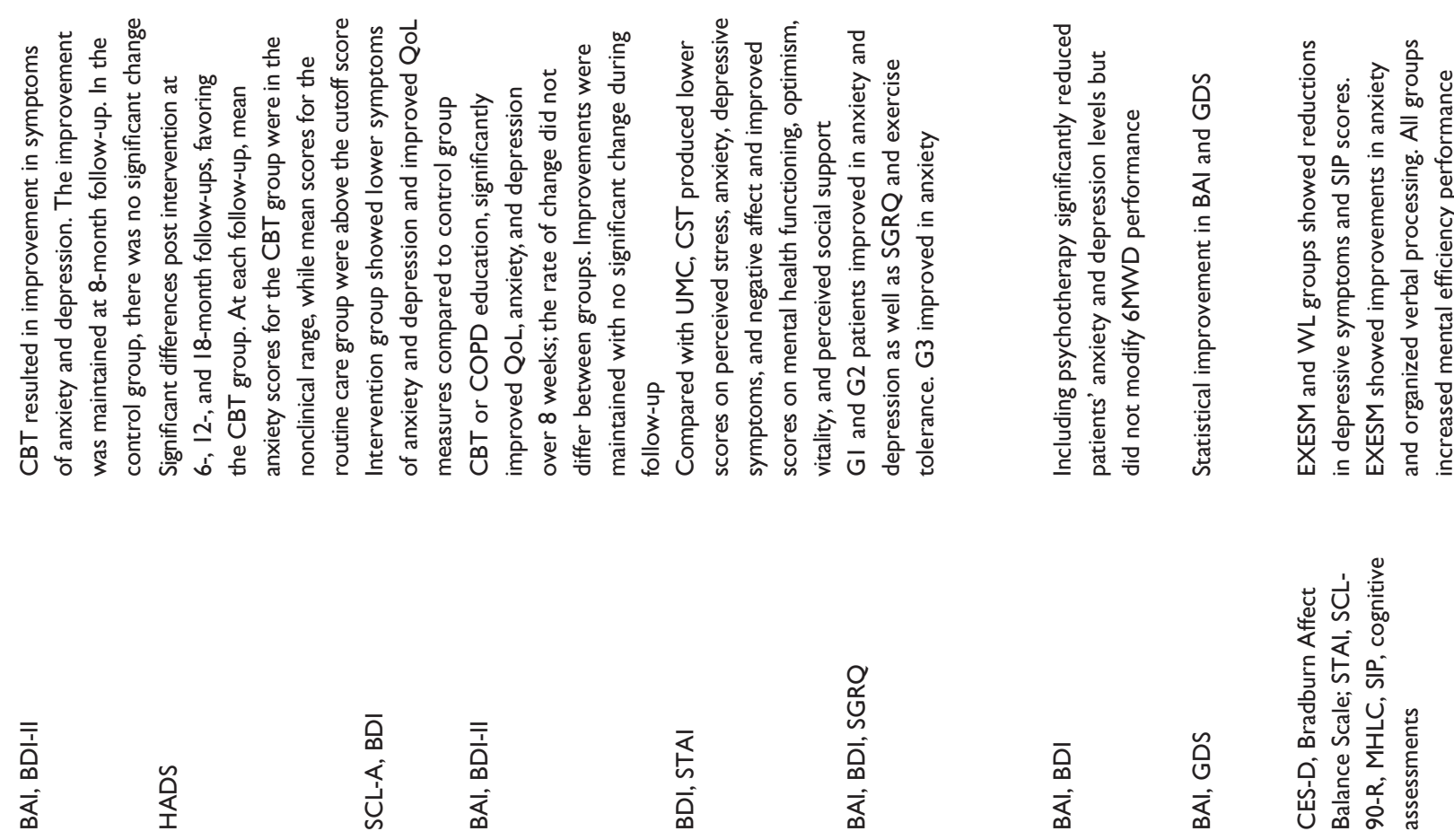

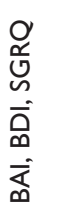
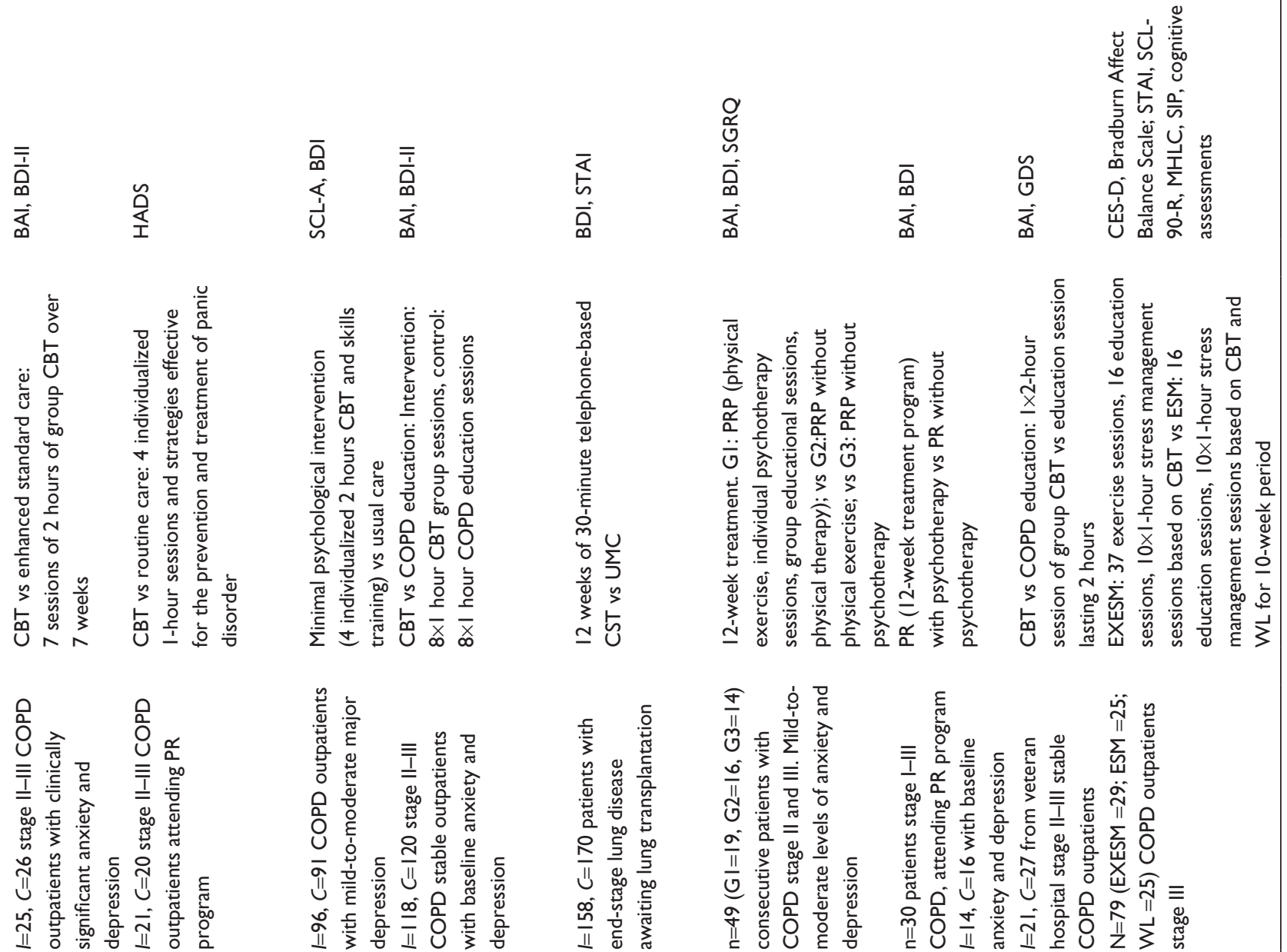

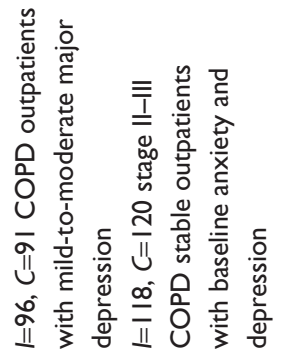

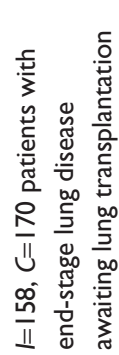

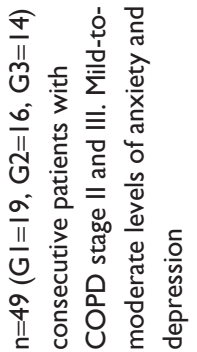
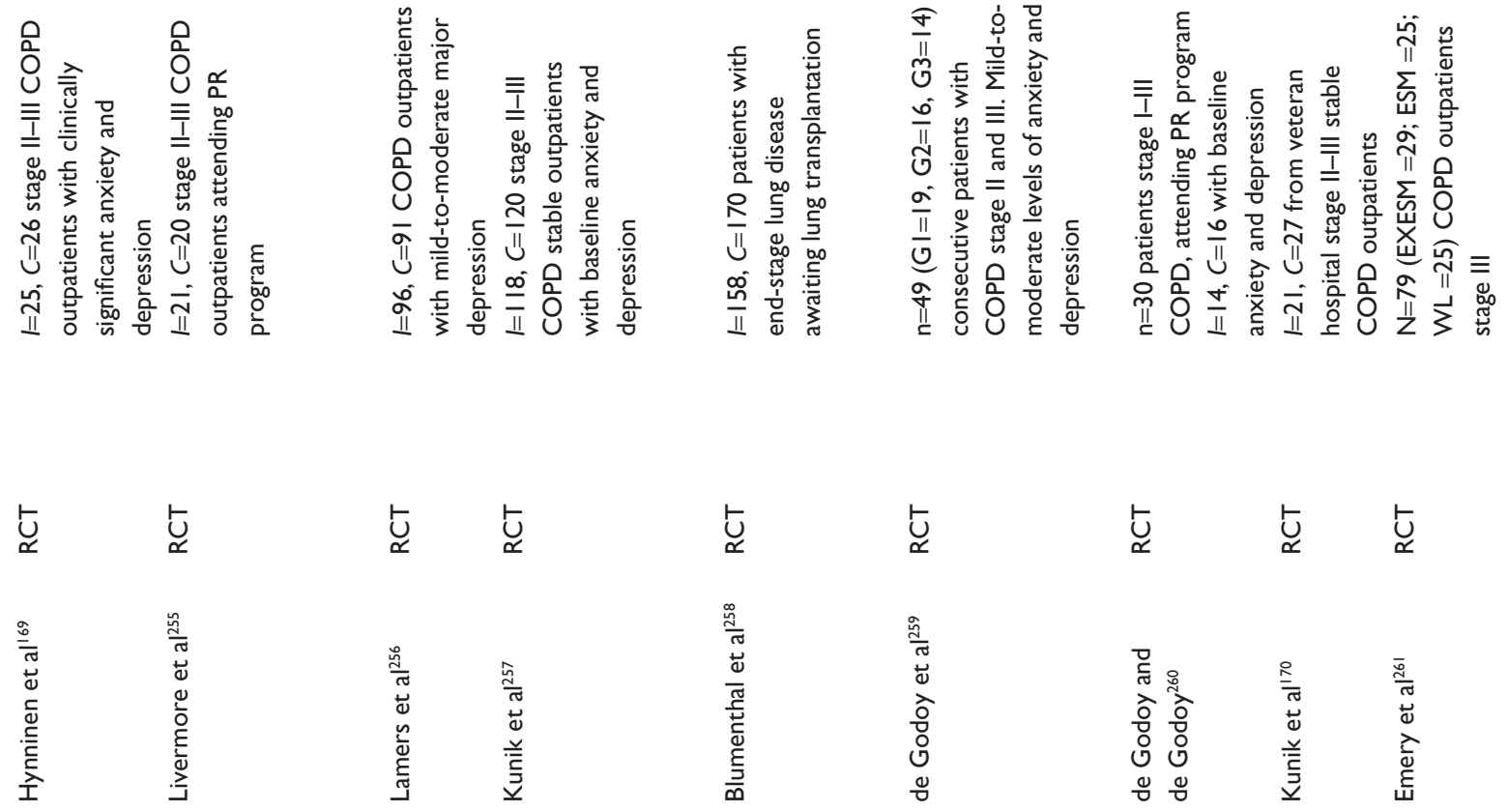


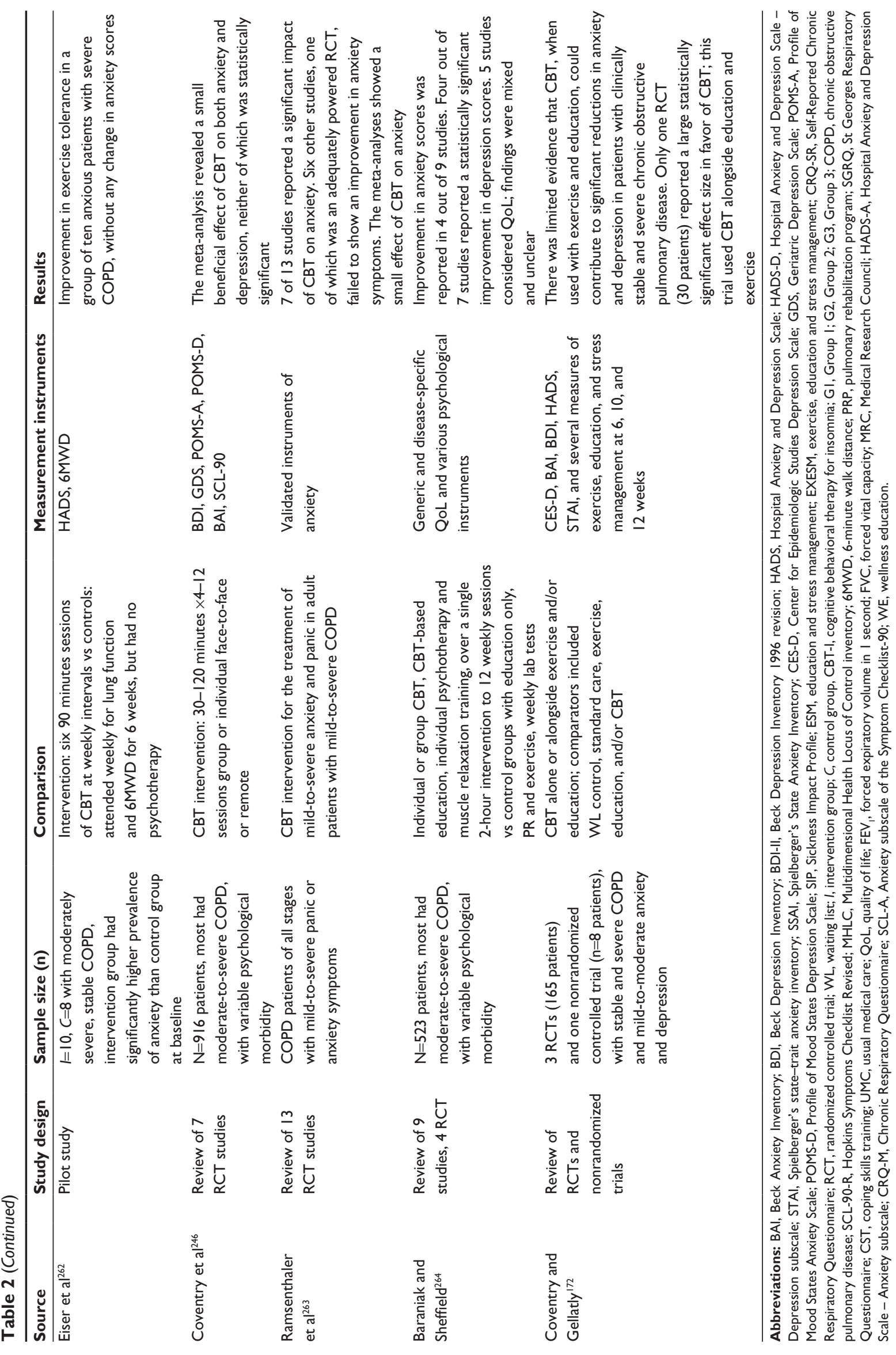




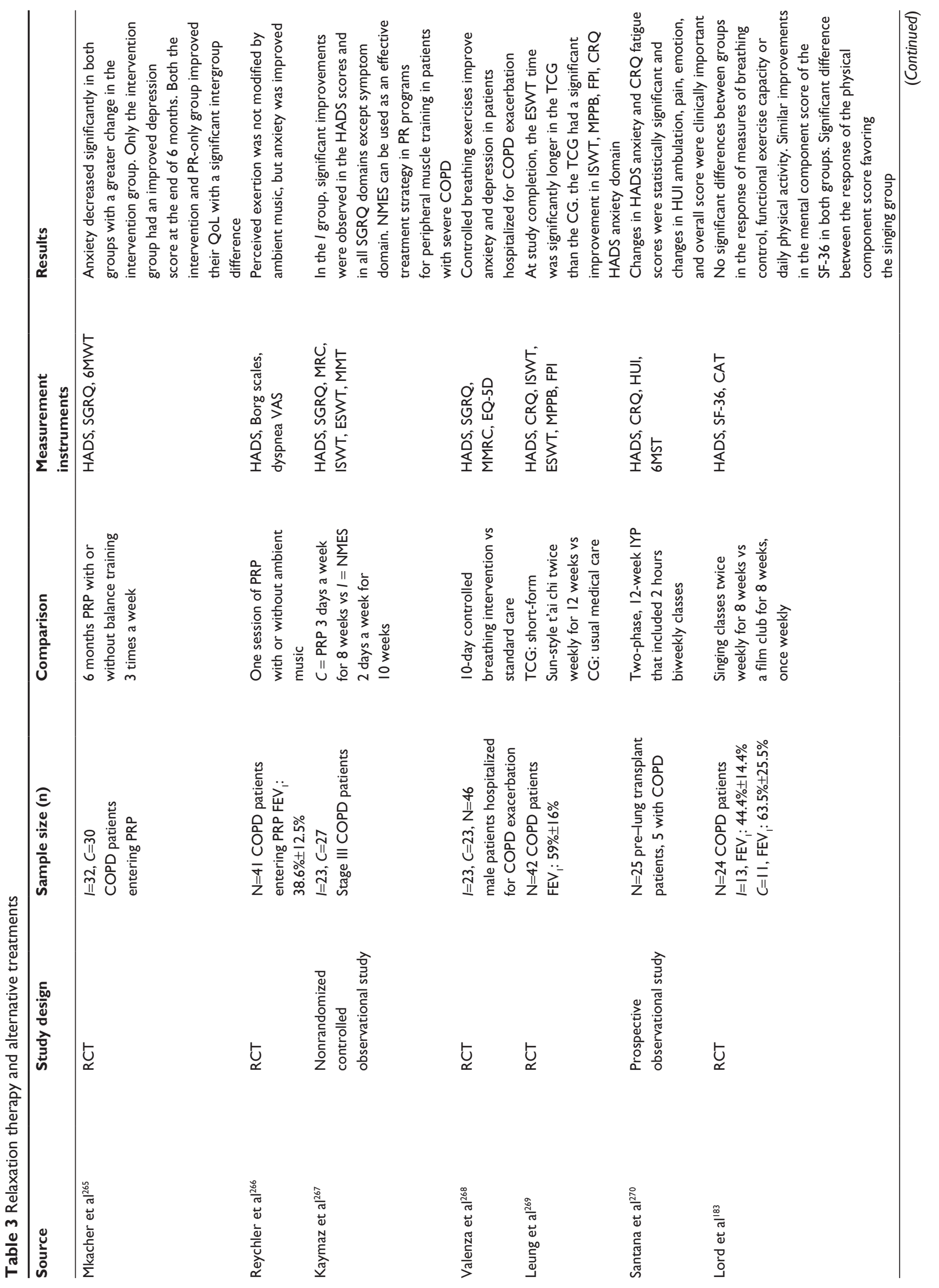




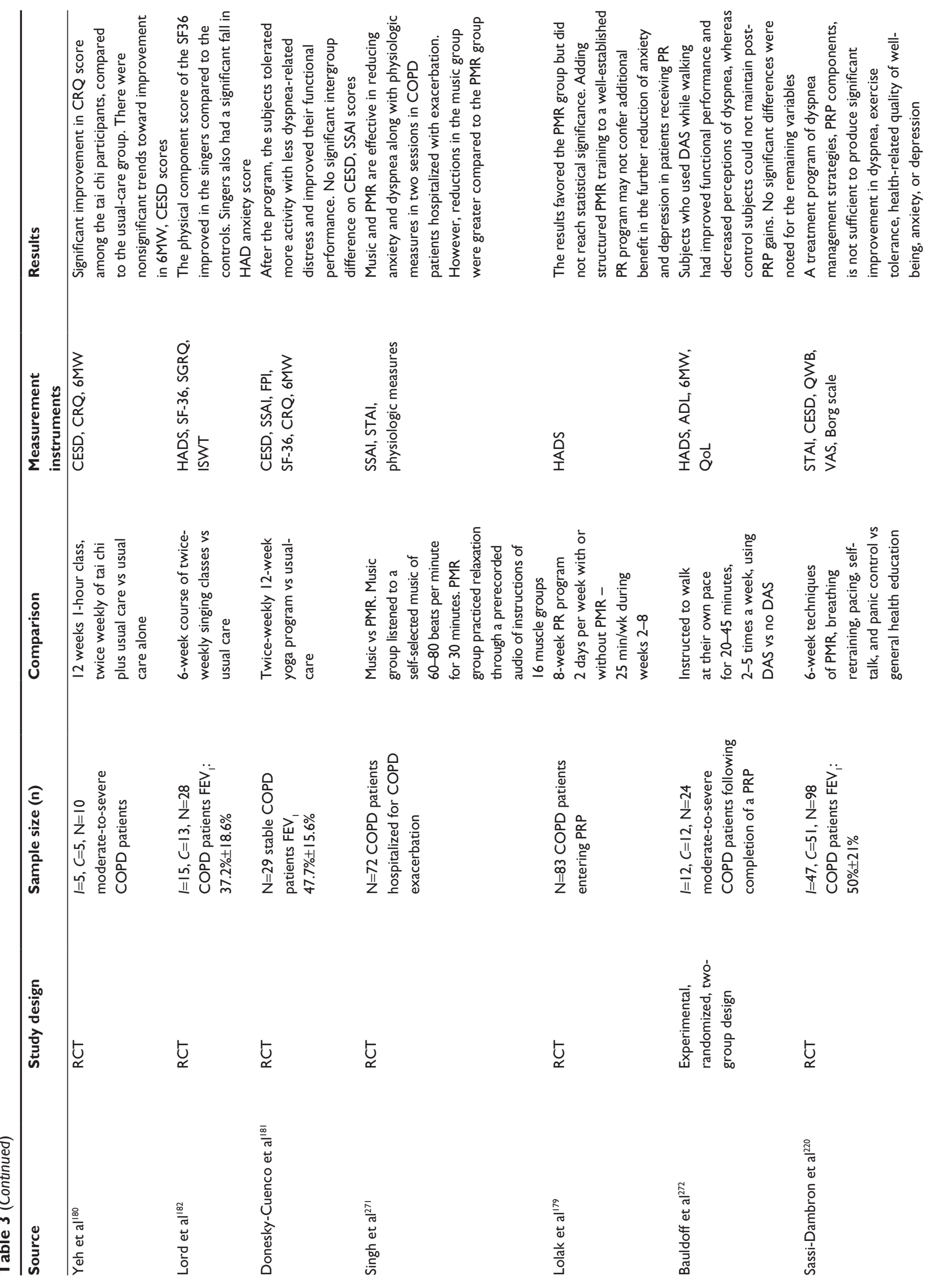




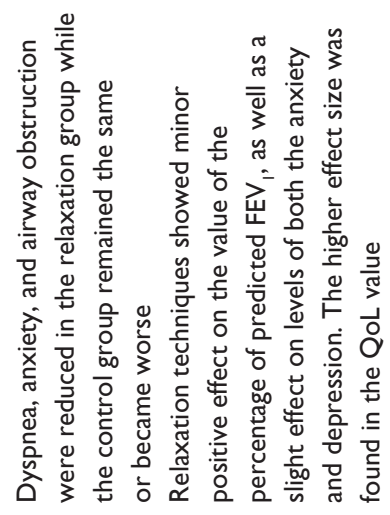

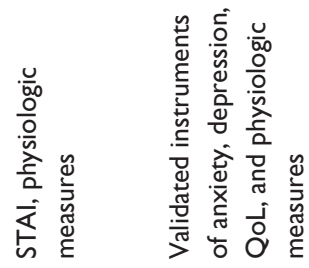

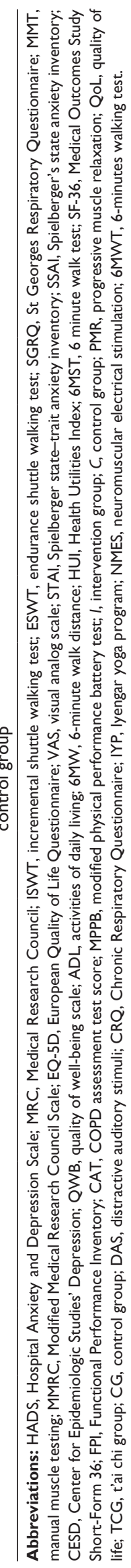

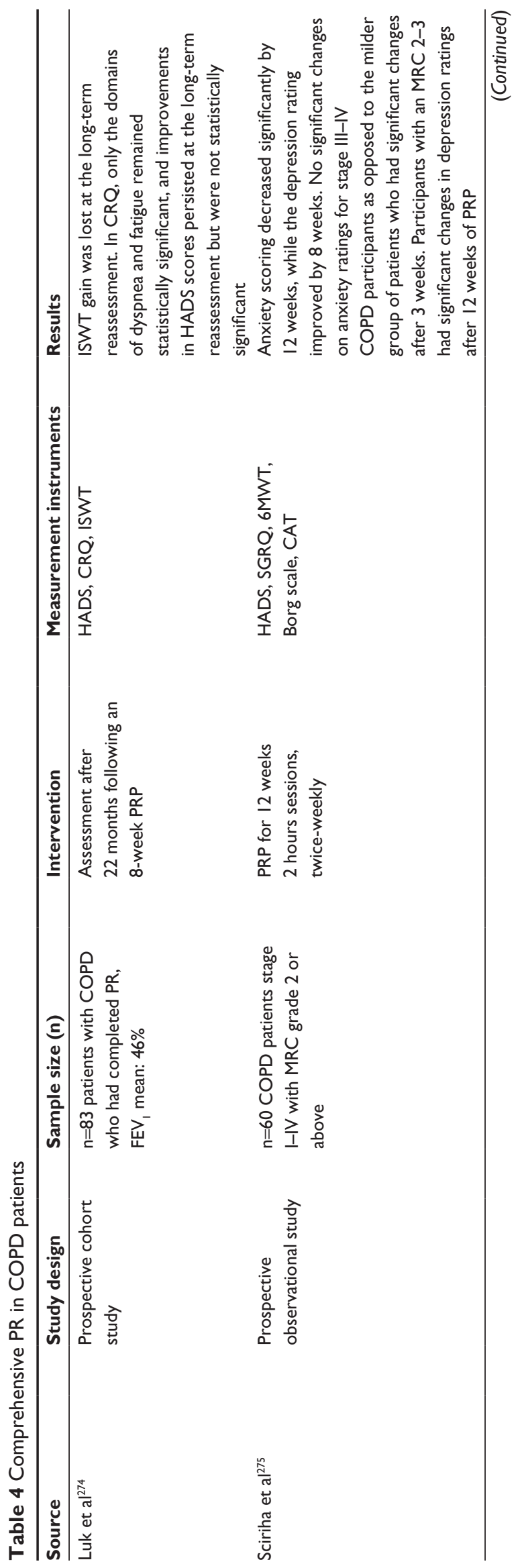




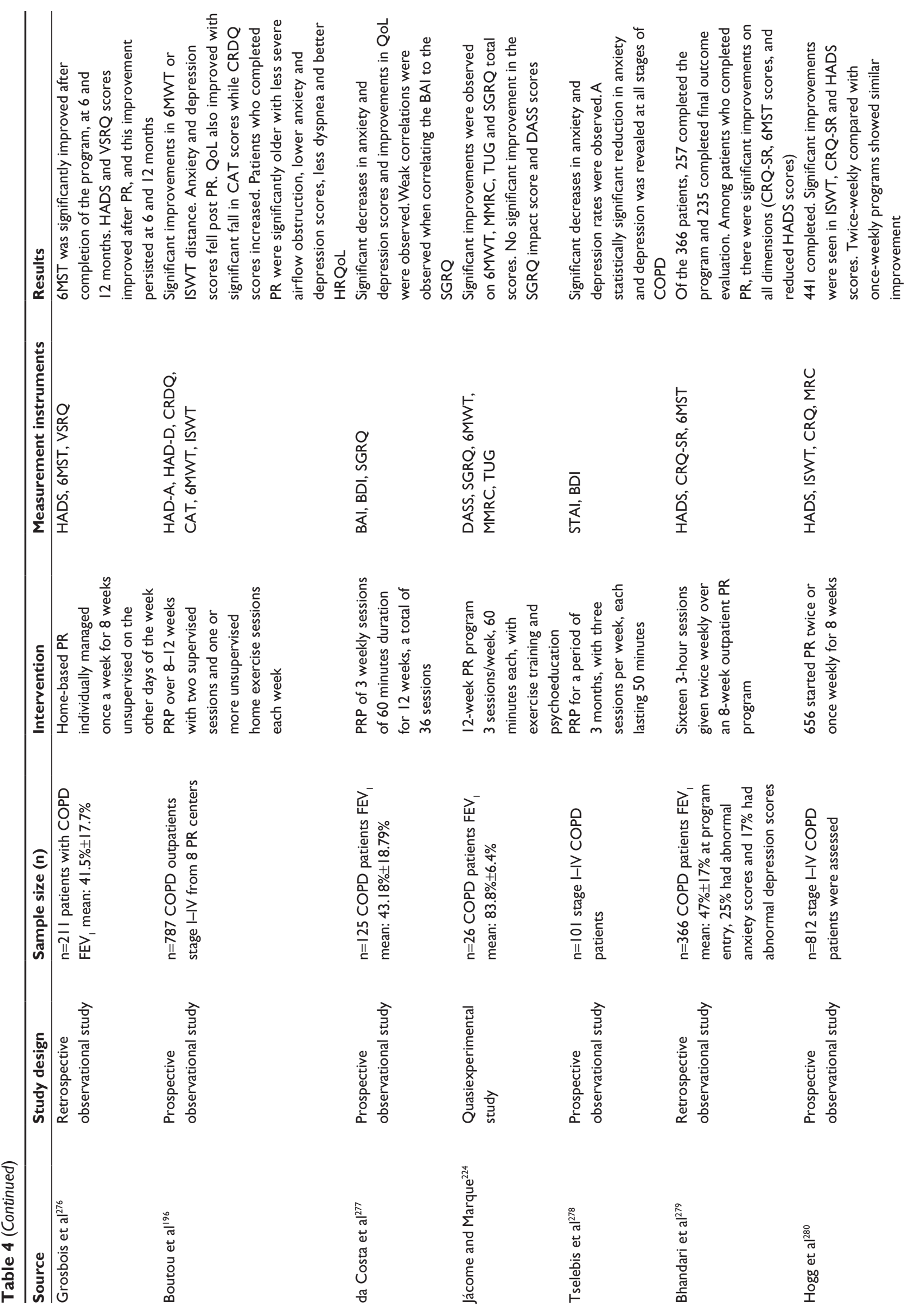



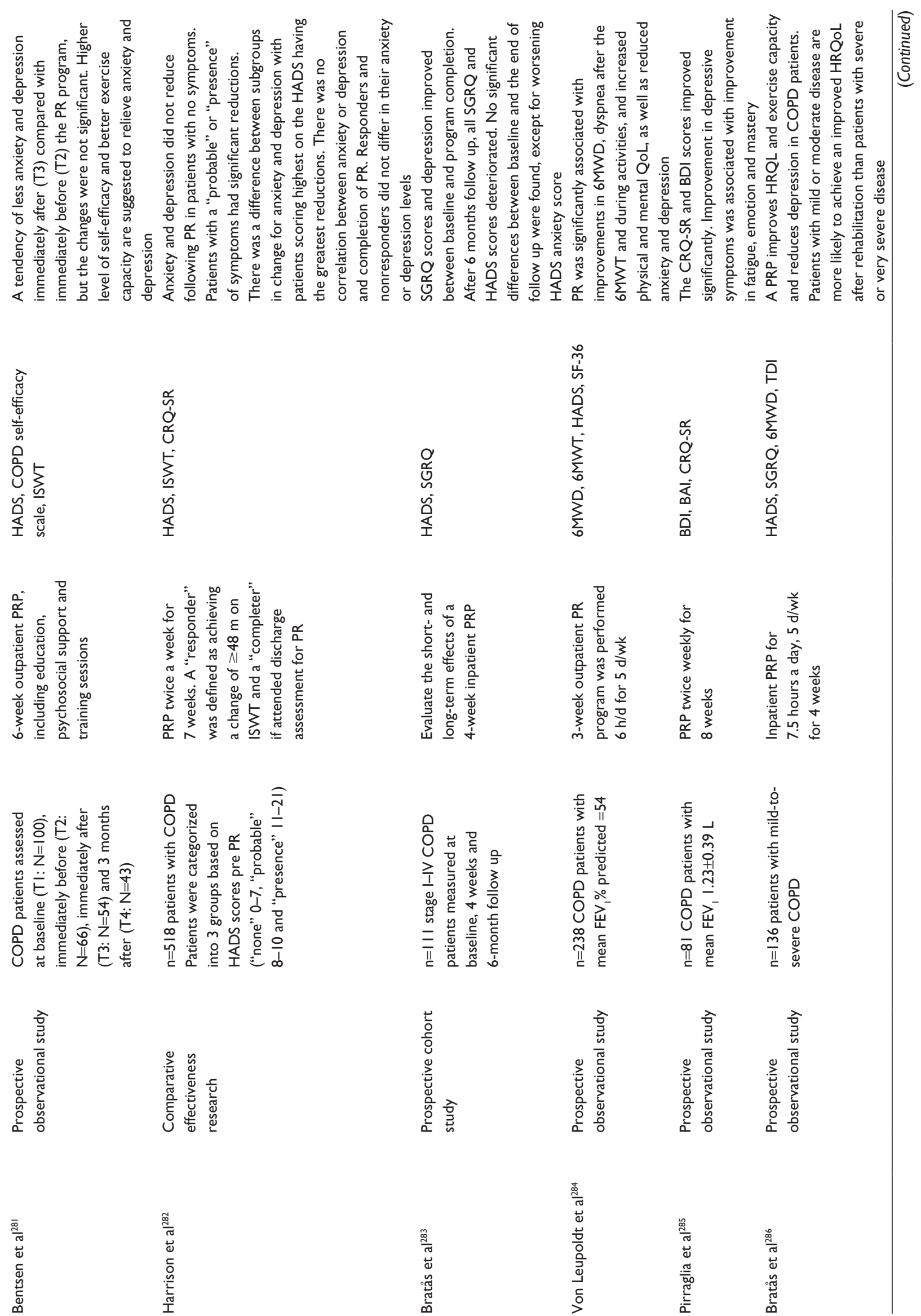

苋
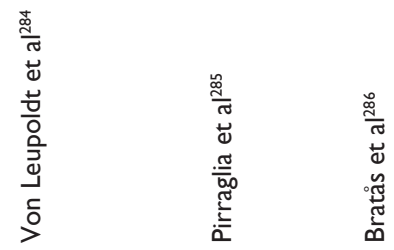


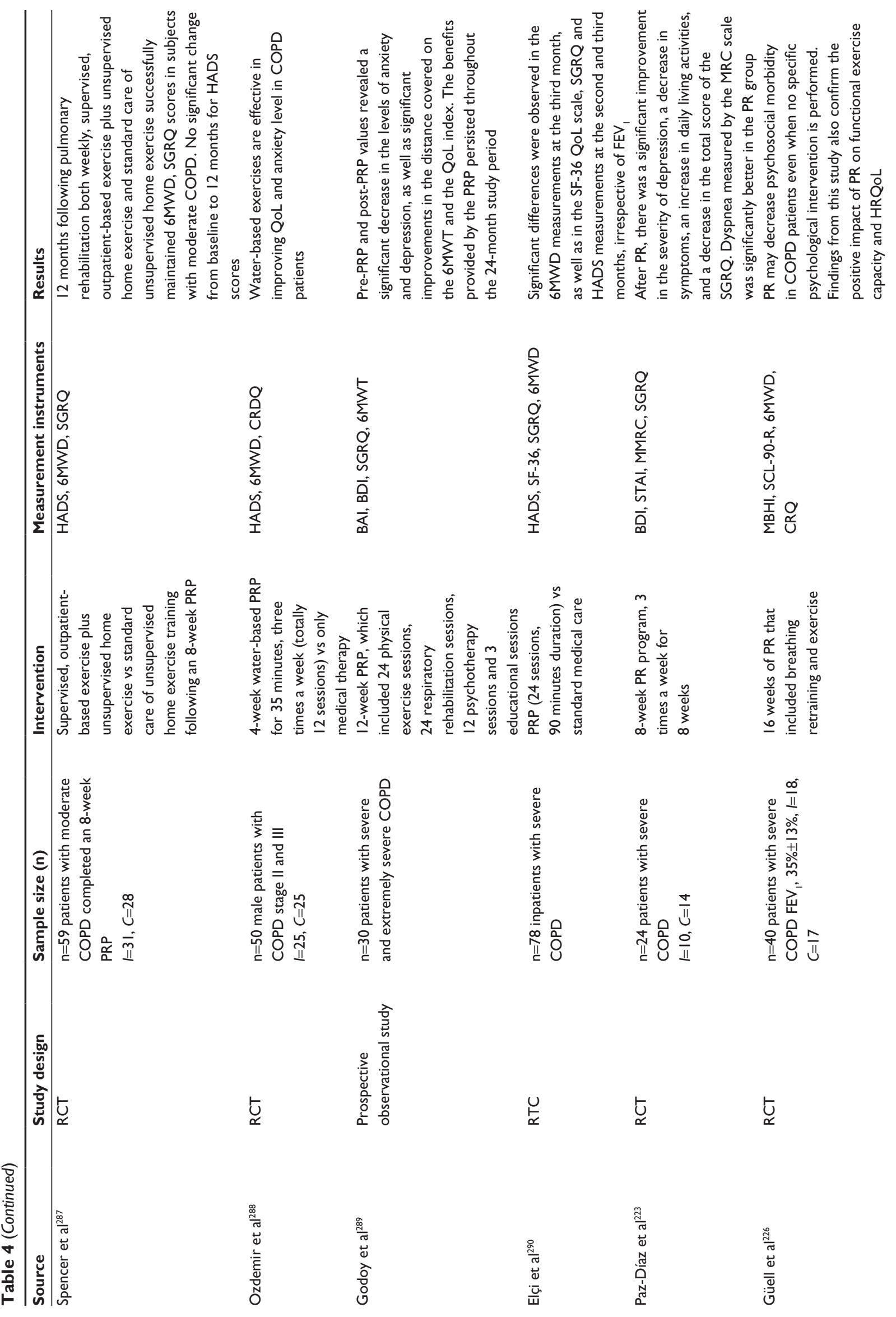



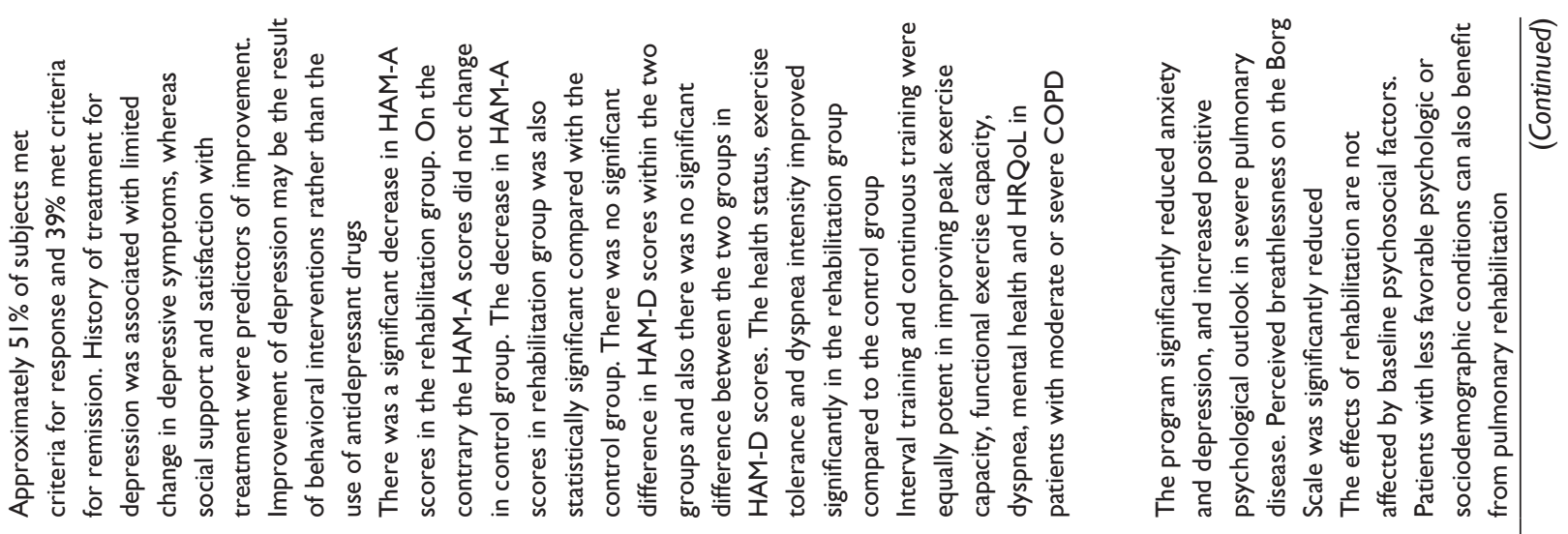

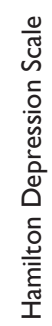

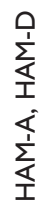

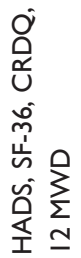

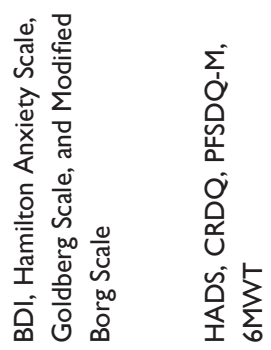

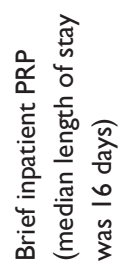
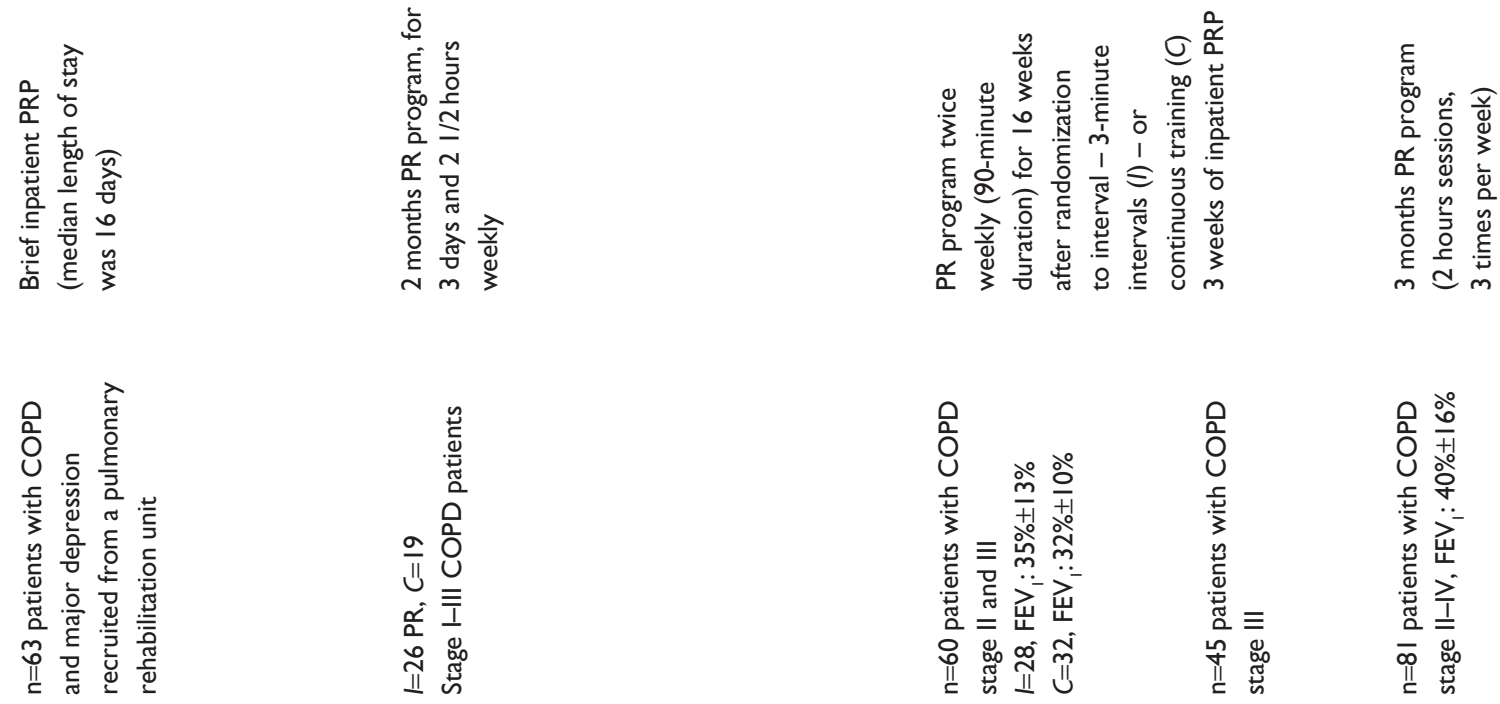

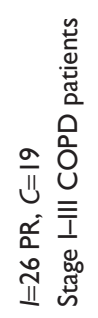
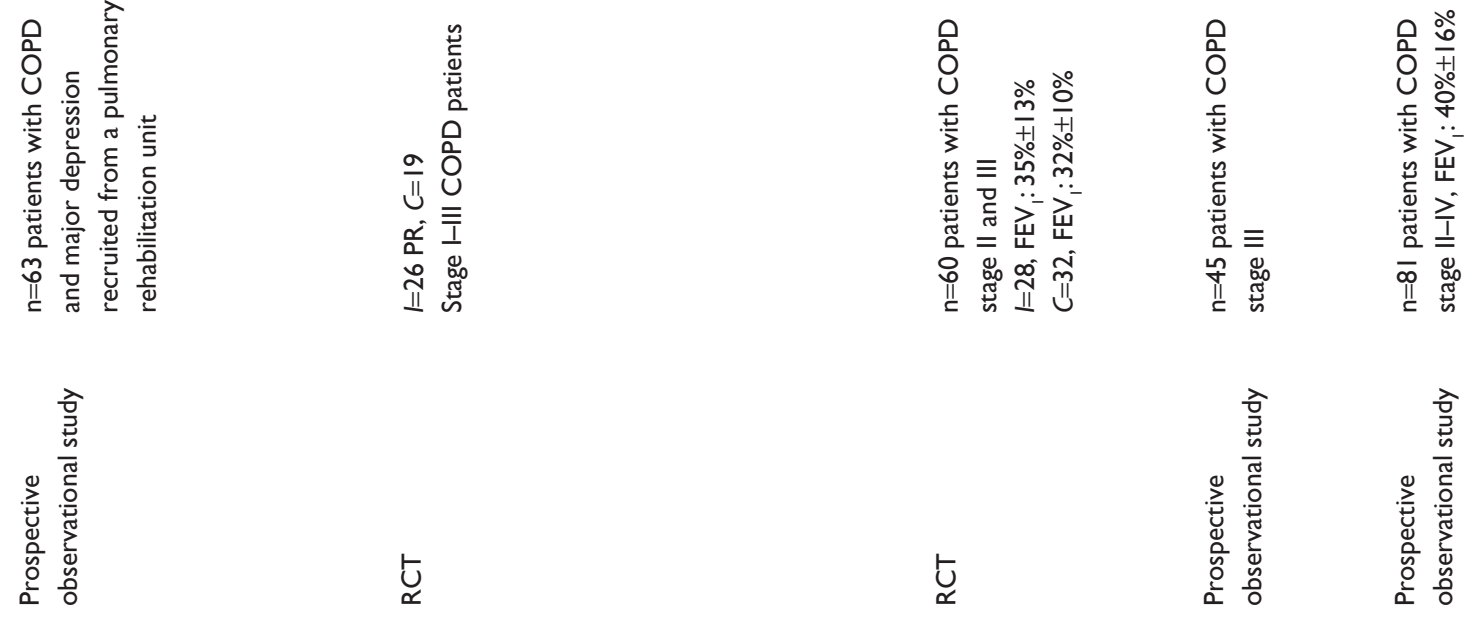

$\underset{\swarrow}{\longleftarrow}$

$\underset{\longleftarrow}{\longleftarrow}$

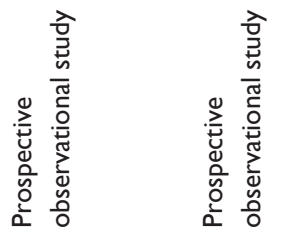

$\frac{a}{0}$
$\frac{\pi}{0}$
$\frac{0}{0}$
$\frac{0}{0}$
$\frac{0}{0}$
$\frac{0}{\alpha}$
$\frac{0}{\alpha}$

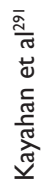

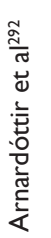

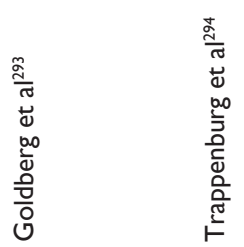




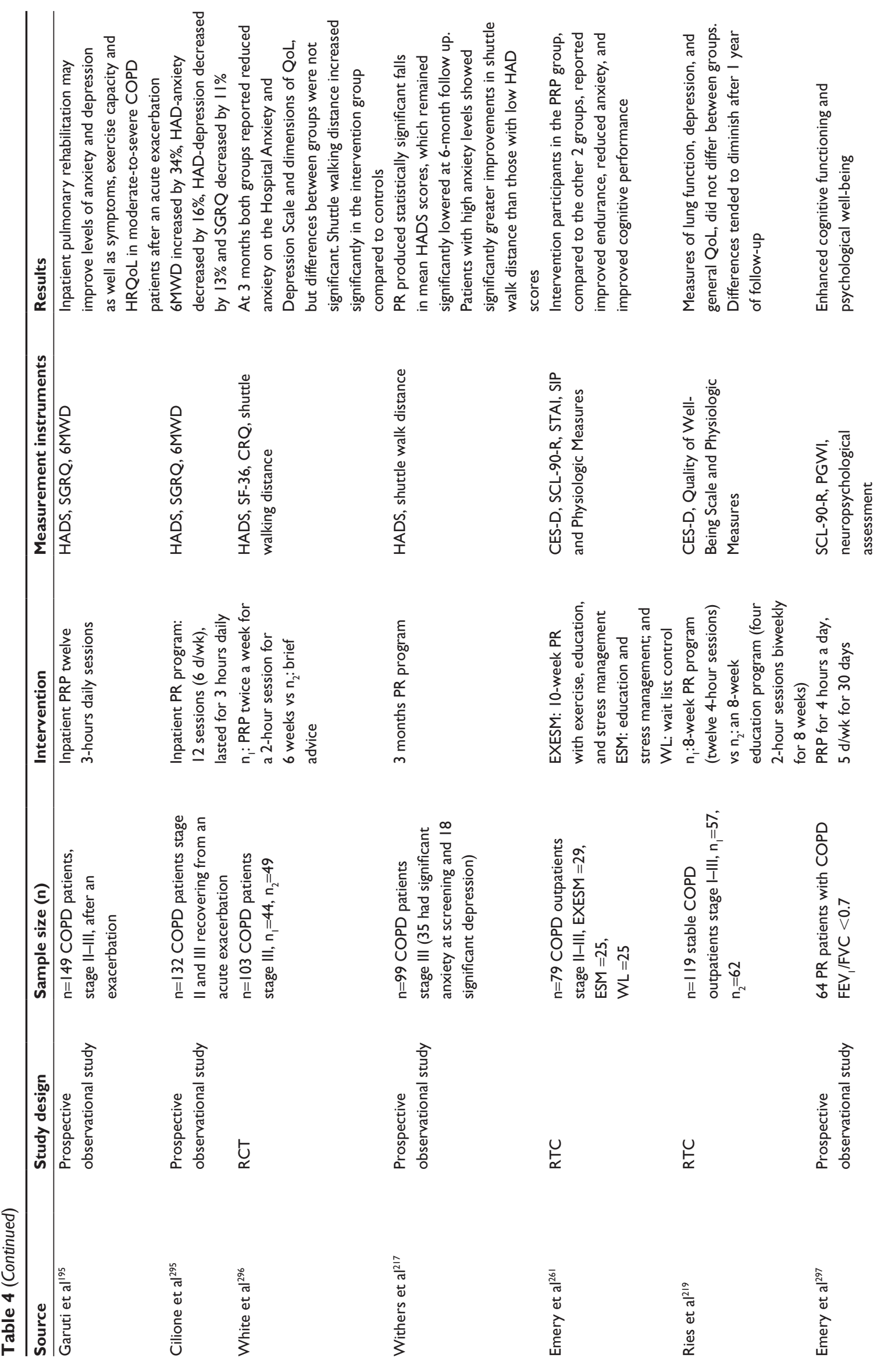



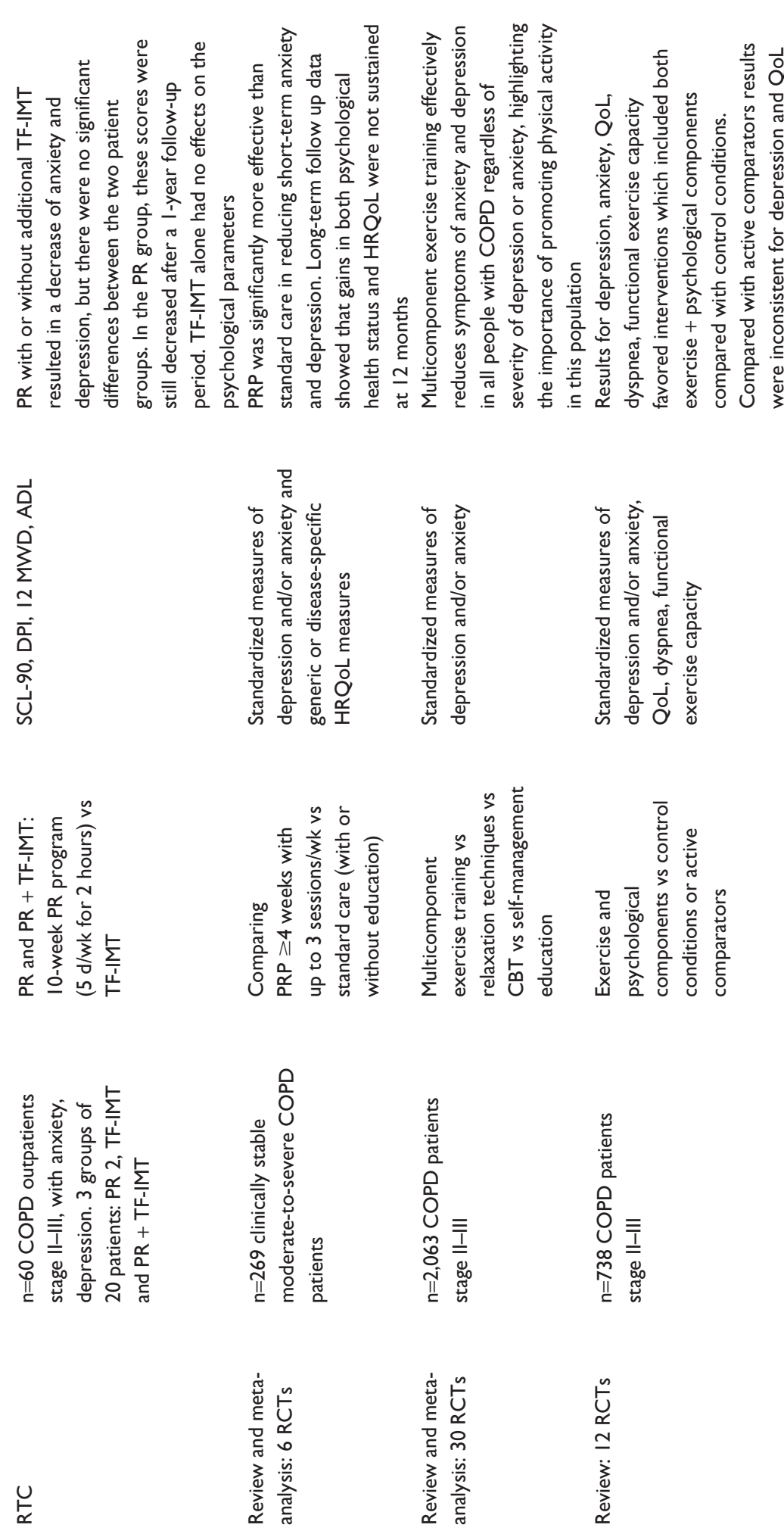

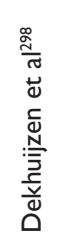
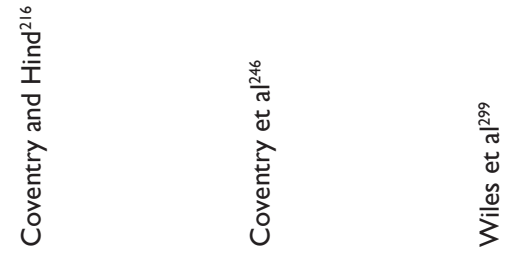

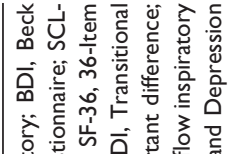

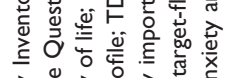

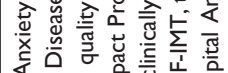

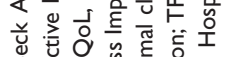

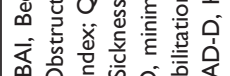

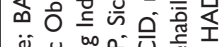

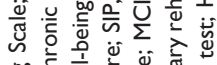

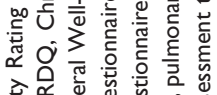

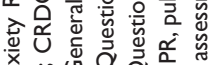

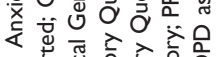

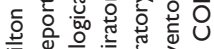

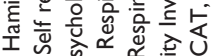

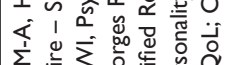
全话过 论

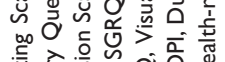

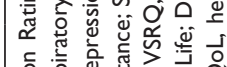

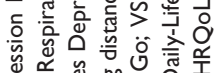

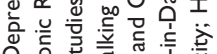
б

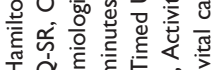

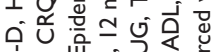

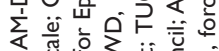

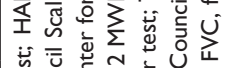

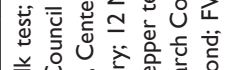

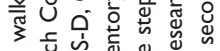

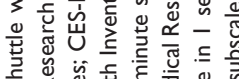

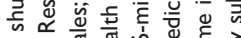

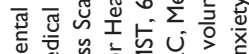

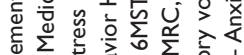

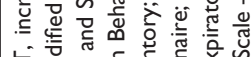

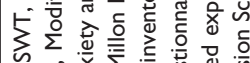

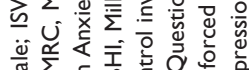

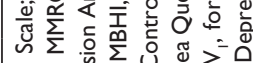

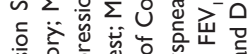

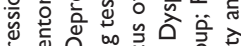

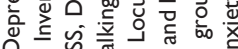

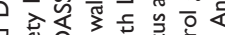

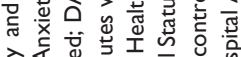

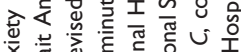

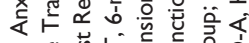

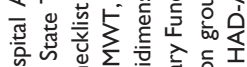

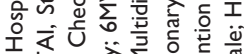

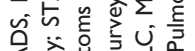

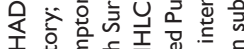

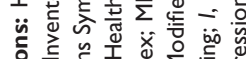

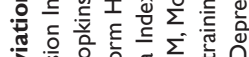

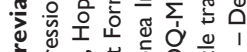

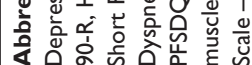


retardation and necessitates support networks and protection against continuous vascular damage. Late-onset depression has been found to be more refractory to treatment with antidepressants, ${ }^{124,125}$ associated with a greater degree of patient apathy, ${ }^{126}$ and less often associated with a family history of depression. ${ }^{127,128}$ On the other hand, early-onset depression is defined as depression that develops prior to the diagnosis of COPD, often during an individual's youth. This type of depression is often reflective of a genetic vulnerability to depression, which increases adolescents' risk for developing addiction to nicotine and presents with more classic symptoms, but might have greater difficulty with smoking cessation. ${ }^{129,130}$

It is also necessary to consider that the prescribed medications should not cause sedation or respiratory depression in patients with chronic respiratory conditions. Plus, the ideal medication should have a low side effect profile, a short half-life with no active metabolites, ${ }^{8}$ and provoke few drug interactions, especially when considering the other already administered medications for COPD. ${ }^{131}$ The most commonly used agents in COPD are $\beta_{2}$-adrenergic agonists and anticholinergic medication. $\beta_{2}$-adrenergic agonists can cause dose-related prolongation of the QT interval and potassium loss. Thus coadministration with some SSRIs and TCAs that can prolong QT interval may result in additive effects and increased risk of ventricular arrhythmias. Also, the anticholinergic action of TCAs may be added to that of anticholinergic bronchodilators used in COPD. Besides pharmacodynamics, pharmacokinetic interactions should be considered, and hence medications with the lowest potential to interfere with cytochrome P450 system should be considered. ${ }^{132}$

In general, antidepressants seem to have little effect on ventilator drive, but caution should be taken while prescribing certain antidepressants (TCAs and mirtazapine) in COPD patients with hypercapnia. ${ }^{12,133}$ On the contrary, benzodiazepines may cause respiratory depression and should be avoided, especially for patients with COPD who are $\mathrm{CO}_{2}$ retainers. ${ }^{134,135}$ A recent prospective study ${ }^{136}$ evaluating the safety of benzodiazepines and opioids in patients with very severe COPD indicated that concurrent use of benzodiazepines and opioids in lower doses $(<0.3$ defined daily doses per day) was not associated with increased admissions or mortality, whereas higher doses $(>0.3$ defined daily doses per day) might increase mortality. Additionally, $\beta$-blockers are contraindicated in these patients, despite their anxiolytic effect due to their potential risk of bronchoconstriction. ${ }^{73}$ Low-potency atypical antipsychotics in very small dosages may alleviate anxiety symptoms in these patients, but should be used with caution as they can have potential neurological and cardiovascular side effects. ${ }^{26}$

Small, placebo-controlled trials of antidepressant drug therapy in patients with COPD did not demonstrate significant treatment effects, with the exception of one study, in 1992, ${ }^{137}$ which indicated high efficacy for nortriptyline in improving short-term outcomes for depression, anxiety, cognitive function, and overall disability. Other TCAs have been tested, such as doxepine, ${ }^{138}$ imipramine, and amitriptyline, ${ }^{139-142}$ with contradictory results. More recent studies ${ }^{143-147}$ have used SSRIs, the current first-line medications for the management of depression, but most suffered from methodological flaws. In few randomized, double-blind, placebo-controlled studies, sertraline, ${ }^{145,146}$ fluoxetine, ${ }^{143,148}$ citalopram, ${ }^{149}$ and paroxetine ${ }^{147}$ offered improvements in quality of life, dyspnea, and fatigue. Start-up side effects with SSRIs include gastrointestinal upset, headache, tremor, and either psychomotor activation or sedation, which is frequently problematic in COPD patients. Treatment timelines necessitate checking the tolerance of medication during 1-3 weeks, then evaluating the response during 2-4 weeks, and if there is response, it is important to complete symptom resolution and move on to continuation and then maintenance phase. In case there is none or inadequate response, augmenting strategies are advised or change of medication is required. ${ }^{14}$ Either way, it is necessary to consult a psychiatrist ${ }^{150}$ in cases of suicidal or self-injurious behavior, psychotic or bipolar depression, or other psychiatric comorbidities (eg, substance abuse, personality disorders). The presence of complex psychological issues, multimorbidity, frailty, and polypharmacy also necessitates integrated and comprehensive approach for the care of these people. ${ }^{151}$

Concerning anxiety, several studies have investigated the effectiveness of specific medications ${ }^{152}$ with contradictory results for buspirone ${ }^{153,154}$ and inconclusive results for SSRIs, even though they are better tolerated and can relieve symptoms of panic, ${ }^{145,146}$ but compliance may be poor. ${ }^{143}$ A recent Cochrane review ${ }^{155}$ on pharmacological interventions for the treatment of anxiety in COPD patients analyzed four studies and found insufficient evidence of benefit for any of medications included. Two studies using SSRIs showed a nonsignificant reduction in anxiety symptoms, ${ }^{144,156}$ while two other studies using TCA and azapirones did not show any improvement. ${ }^{138,154}$ Anticonvulsants such as gabapentin have also been prescribed for the treatment of anxiety symptoms in COPD patients. ${ }^{73}$

Some authors report ${ }^{143,157}$ that patients with COPD and psychiatric comorbidity are reluctant to take yet another 
medication, possibly because of stigma associated with the disease or denial, and as mentioned before, data supporting the efficacy of medication-only treatment are extremely limited. ${ }^{158,159}$

When implementing treatment strategies for COPD patients, it is important to remember that there is a greater possibility for medical comorbidities, increased risk for medication interactions, and greater physical debilitation than the community population. ${ }^{160}$ An overview of studies on pharmacological treatment for anxiety and depression in COPD patients is summarized in Table 1 .

\section{Psychotherapeutic interventions}

Patients prefer nondrug treatments, ${ }^{161}$ and clinical guidelines ${ }^{117,162}$ promote nonpharmacological interventions as first-line therapy for depression and anxiety in people with long-term conditions. NICE recommends use of low- (eg, self-help programs) or high-intensity (individual or group CBT) psychosocial interventions depending on the severity of mood symptoms. ${ }^{163}$ Both individual and group therapy psychological interventions are useful in promoting more adaptive coping in COPD patients. ${ }^{92}$

\section{CBT}

Evidence suggests that individualized or group CBT is the treatment of choice for addressing the maladaptive coping in the COPD patient with mental health difficulties, because of the time-limited and action-oriented nature of the intervention. ${ }^{164}$ According to this psychotherapeutic approach, emphasis is given to the effect of cognitions on mood and behavior. This model of psychotherapy assumes that maladaptive, or faulty, thinking patterns cause maladaptive behavior and "negative" emotions. Maladaptive behavior is behavior that is counterproductive or interferes with everyday living. ${ }^{14}$ The treatment focuses on changing an individual's thoughts (cognitive patterns) in order to change his or her behavior and emotional state. Therapists attempt to make their patients aware of these distorted thinking patterns, or cognitive distortions, that fuel anxiety and depressive symptoms and change them (a process termed cognitive restructuring). ${ }^{14}$ Therapy focuses on helping patients discover alternative solutions and promote more adaptive coping styles in order to overcome adversities and effectuate operational techniques to address their problems. ${ }^{165-167}$

Mental health guidelines recommend CBT as the treatment of choice for a range of mood and anxiety disorders and as an adjunct to other treatments. Low-intensity CBT-based psychosocial interventions are recommended for people with mild-to-moderate anxiety and/or depression, whereas high-intensity psychological interventions using CBT in combination with medication is recommended for people with moderate-to-severe depression. ${ }^{162,163}$ Not all aspects of CBT may be necessary to produce a therapeutic effect. Purely behavioral interventions can be as effective as CBT for patients with depression. ${ }^{168}$

Some studies report that there is potential for psychological interventions to reduce anxiety and depression in people with COPD. ${ }^{169,170}$ A recent meta-analysis of four CBT studies for anxiety and depression in COPD patients indicated improvements in these symptoms. ${ }^{171}$ Also, based on randomized controlled trials, CBT resulted in improvement in symptoms of anxiety and depression (Table 2), especially when used with exercise and education. ${ }^{172}$

\section{Group psychotherapy}

Group psychotherapy is a financially attractive approach in response to the realities of limited resources, regardless of its theoretical orientation, because it involves fewer therapists, less therapist per person-hours, and serves more patients.

The group context and group process, if explicitly utilized within the principles of system dynamics, offers valuable healing opportunities. ${ }^{14}$ Therapeutic principles, ${ }^{173,174}$ termed "therapeutic" factors, include the experience of relief from emotional distress through the free and uninhibited expression of emotion, feeling a sense of belonging, acceptance, and validation. Within a context that reflects the individual's perception of reality, group members share experiences and feelings and develop social skills through a modeling process.

The therapist's interventions facilitate group activities by taking advantage of the inherent assets of the team, ensuring that it runs efficiently with appropriate boundaries being maintained. ${ }^{14}$

\section{Relaxation therapy and alternative treatments}

Relaxation therapy encompasses a range of techniques such as breathing exercises, sequential muscle relaxation, biofeedback, guided imagery, distraction therapy, hypnosis, meditation/mindfulness, and physical posture therapy. ${ }^{175,176}$ Often, some of these techniques are components of PR or are used as an adjunct to other therapies (eg, CBT). ${ }^{12}$ The purpose of this therapy is to promote psychological change by effectively managing physiological changes accompanying anxiety. In other words, regulation of the sympathetic nervous system and management of the stimulation of certain regions 
of the hypothalamus facilitate the relaxation response. ${ }^{177}$ In this perspective, relaxation techniques are often used to inhibit anxiety, increasing the patient's perception of selfcontrol or modulating his or her emotions, in order to promote the perceived well-being of the subject.

A meta-analysis of trials with relaxation-based therapies for COPD patients indicated statistically significant beneficial effects on both dyspnea and psychological well-being. ${ }^{178}$ Another recent meta-analysis on the effects of relaxation techniques, of 25 randomized controlled trials including both inpatients and outpatients with COPD, showed a minor positive effect on respiratory function as well as a slight effect on levels of both the anxiety and depression. The higher effect size was found in the quality of life value. ${ }^{176}$

Several other studies have investigated other types of relaxation approaches. ${ }^{179} \mathrm{In}$ a pilot study, the authors argued that the introduction of Tai Chi exercises was worth exploring in patients with COPD, ${ }^{180}$ while in another study, ${ }^{181}$ Yoga exercises were performed. Singing lessons have also been used as an intervention in patients with COPD. ${ }^{182,183}$ The basic theory is that singing lessons could improve quality of life or functional status in these patients. ${ }^{184}$ Regarding these less traditional interventions, there is still lack of certainty about their applicability, their long-term effectiveness, the active component (physical or psychological), and how they can be incorporated into standard care. ${ }^{185}$ An overview of studies on relaxation therapies and alternative treatments for anxiety and depression in COPD patients is summarized in Table 3.

\section{PR}

Treatment strategies include PR, because it improves patient's ability to participate in stress-reducing activities and increases their sense of self mastery. It also improves quality of life by increasing patients' perception of available social supports. ${ }^{186}$ According to the American Thoracic Society and the European Respiratory Society, $\mathrm{PR}^{187}$ is an evidence-based multidisciplinary and comprehensive intervention for patients with chronic respiratory diseases who are symptomatic and often have decreased daily life activities.

The ideal patient for PR is one with functional limitations, moderate-to-severe lung disease, who is stable on standard therapy, without comorbid serious or unstable medical conditions, willing to learn about the disease, and motivated to devote time and effort necessary to benefit from a comprehensive care program. ${ }^{188}$

The interdisciplinary team of health-care professionals in PR may include physicians, nurses, respiratory and physical therapists, psychologists, and exercise specialists. ${ }^{151}$
PR programs operate by means of progressive exercise, training of respiratory function, and psychoeducation, so that patients obtain better exercise tolerance with less dyspnea. The goal is to restore the patient to the highest possible level of independent function. ${ }^{189}$ Patients are educated about their disease and learn breathing techniques to reduce air hunger and exercises to optimize oxygen use, and this in turn improves exercise tolerance. Key outcomes such as exercise capacity and overall health-related quality of life may be accurately measured. ${ }^{190-192}$

Exercise-based PR programs have been the most consistently helpful interventions for minor mood symptoms in COPD patients, ${ }^{193-195}$ but the greatest improvements in anxiety and depression are usually in those with the highest scores at baseline. ${ }^{196}$ The paradox is that patients most likely to benefit from PR appear least likely to complete it. ${ }^{197,198}$ It is important therefore to be able to identify patients with COPD who may need additional support to complete a PR program in order to broaden benefit to all.

Several mechanisms have been hypothesized to explain the effect of exercise rehabilitation on mental health symptoms. Biological mechanisms associated with exercise activity include changes in central monoamine function, ${ }^{199-204}$ enhanced hypothalamic-pituitary-adrenal axis regulation, increased release of endogenous opioids, ${ }^{205-207}$ and reduced systemic inflammation. ${ }^{208,209}$ In this way, regular physical activity may reduce depression and anxiety among patients undergoing PR. In addition, behavioral mechanisms ${ }^{210-215}$ associated with exercise activities operate synergistically to produce reductions of symptoms. Such mechanisms include active distraction from worrying thought patterns (rumination), increase of self-efficacy by providing patients with a meaningful mastery experience, and provision of daily pleasant events and regular social contact and support.

A recent systematic review ${ }^{216}$ showed that $P R$ is beneficial in reducing anxiety and depressive symptoms, but the longterm benefit is unknown. Studies combining antidepressant pharmacotherapy or psychotherapy indicated more effective results than PR alone. ${ }^{217,218}$ Because both depression and anxiety may be manifested in physical symptoms during the course of a PR program, collaborative care is essential among all involved health-care professionals to ensure that patients' problems are identified, evaluated, and treated.

The majority of PR programs have a primary exercise focus in order to recondition the legs and other peripheral muscles, making them more efficient as to oxygen needs, and thereby requiring relative less breathing to satisfy these oxygen requirements. ${ }^{219}$ Additionally, PR programs teach 
breathing control exercises to patients and educate them in recognizing an impending dyspnea attack and preventing it, or controlling it, so they lose their fear of exerting themselves. ${ }^{220}$

In PR settings, patients learn that they can have increases in activity levels and in dyspnea without perceiving that increase in dyspnea as a medical crisis. When patients experience their symptoms safely, they become desensitized by learning to distinguish between physical and emotional symptoms. Then, these patients can gradually take responsibility for the day-to-day management of their condition, with a result of improving their confidence, control, and autonomy. ${ }^{221}$

PR should be offered to all COPD patients irrespective of disease severity, since they all get improvements, ${ }^{222,223}$ from mild COPD ${ }^{224}$ to severe-to-very severe lung disease. ${ }^{225,226}$ Emphasis should be given to exercise training with respect to patients with mild-to-moderate disease, but for patients with severe-to-very severe COPD, PR programs should be tailored mostly toward dyspnea management and psychological support. 227,228

In sum, the preponderance of recent evidence supports the utility of PR for reducing depression and anxiety and enhancing cognitive performance, but it is necessary to maintain the physical activity regimen to sustain the gains in physical fitness, mood, and cognitive performance, otherwise a relapse is inevitable. ${ }^{193}$ Representative studies with PR programs for COPD patients are summarized in Table 4.

\section{Discussion and recommendations}

Mental health problems in COPD remain underdiagnosed and undertreated. ${ }^{229}$ Although more than one-third of individuals with COPD experience comorbid symptoms of depression and anxiety, ${ }^{230}$ available evidence suggests that less than onethird of COPD patients with such comorbidity are receiving appropriate treatment for this. ${ }^{231}$ Every clinician caring for patients with COPD should have a high level of suspicion regarding the presence of mental health comorbidities since they are associated with poorer outcomes. ${ }^{230}$

The first step to improve practice is to achieve earlier and more accurate diagnosis. It is not clear when screening should be done ${ }^{232,233}$ and if it should be carried out with all COPD patients or just to those at higher risk of these comorbidities. ${ }^{29}$ Current screening tools for anxiety and depression in patients with COPD were primarily validated for patients with other chronic diseases. ${ }^{234-237}$ The Hospital Anxiety Depression and the Beck Depression and Anxiety Inventory scales have been recommended as the preferable choice of screening tools for anxiety and depression in patients with COPD. ${ }^{29}$ Clinicians should be aware of the somatic overlap between anxiety and/or depression and COPD. ${ }^{238,239}$

Mild-to-moderate symptoms of anxiety and/or depression should not be ignored, and treatment should be considered. High-scoring patients should be referred to a mental health specialist for a comprehensive diagnostic assessment using structured clinical interviews. It is well known that physiological, functional, and psychosocial consequences of COPD are only poorly to moderately related to each other. ${ }^{240}$ This means that a comprehensive assessment of the effects of COPD requires a battery of instruments that not only tap the disease-specific effects, but also the overall burden of the disease on everyday functioning and emotional well-being. Accurate assessment will ensure that treatment modalities are targeting the specific mental health problem taking into account individual factors, such as genetic predisposition, nicotine addiction, social support, other comorbidities, etc.

Identification of mental health problem should guide the choice of pharmacological, psychotherapeutic, or other suitable intervention (Figure 1). While treatment guidelines highlight the importance of recognizing and treating depression and anxiety in patients with COPD, there are few clear evidence-based pathways for the treatment of depression and anxiety. A GOLD report states that there is no evidence that anxiety and depression should be treated differently in the presence of COPD, so at this point of time guidelines are based on treatment of depression and anxiety for the general population.

In clinical practice, bidirectional associations between depression and/or anxiety and COPD imply the need to promote approaches that integrate physical and mental health care. The NICE has published clinical guidelines for managing depression in people with long-term conditions. ${ }^{113}$ The guidelines review the evidence for the associated servicelevel interventions (such as stepped care and collaborative care) and psychosocial, psychological, and pharmacological interventions.

According to reviews and meta-analysis, ${ }^{185,230}$ current evidence for treatment options to reduce anxiety and depression in patients with COPD include pharmacological treatments, CBT, PR, relaxation therapy, and personalized interventions. ${ }^{241,242}$ PR has extensive evidence supporting its benefits, and it has been shown to significantly reduce symptoms of both anxiety and depression in COPD patients. ${ }^{216}$ Although there is lack of strong evidence for the efficacy of pharmacological treatment in patients with COPD with comorbid depression and anxiety, adding a depression- or anxiety-targeted treatment to the PR 
Assessment: Mental health symptoms

Severe anxiety and major depression, suicidal ideation
Management: Appropriate intervention

Medication, high-intensity psychological interventions, combined treatments, collaborative and inpatient care

Medication, high-intensity psychological interventions, combined treatments, collaborative care and referral for further assessment and pulmonary rehabilitation
Persistent subthreshold anxiety and/or depressive symptoms or mildto-moderate anxiety and/or depression

Time-limited minor depressive and/or anxiety symptoms
Persistent subthreshold anxiety and/or depressive symptoms or depression with inadequate response to initial interventions; moderate and severe anxiety and/or depression

Figure I Recommendations for appropriate interventions following assessment of mental health symptoms in patients with COPD.

program may have additive therapeutic benefits. ${ }^{225}$ Maximizing the efficiency of services is important as limited health resources allocated to PR programs mean that not every patient with COPD who might benefit has access to them.

In recent years, a model of care termed the collaborativecare model has been found to be associated with significant improvement in depression outcomes. ${ }^{243-245}$ Collaborativecare models that focus on building partnerships between mental health and other professionals to foster integration of care for people with complex morbidities present a fruitful framework for the management of mental health in COPD. ${ }^{29}$ By definition, PR is an example of a collaborative-care model. In particular, the integration of PR and psychological therapies, such as CBT, has the potential to lead to significant patient benefits. ${ }^{230}$ Contemporary research suggests that complex psychological and/or lifestyle interventions, which include a PR component, have the greatest effects on depression and anxiety in patients with COPD. ${ }^{246}$

Most people with stable COPD are managed in primary care where recognition, assessment, and initial management of anxiety and depressive symptoms can be provided. ${ }^{229}$ Tailoring mental health interventions to adapt not only to the unique needs of COPD patients but also to the current primary care setting is necessary. From the earliest consultations, we should acknowledge patients' beliefs about their COPD and its management to better assess their likely responsiveness to treatment. We can then more effectively deliver from a menu of interventions in order to improve outcomes. Continuity of care implies that when COPD patients need hospitalization for the treatment of exacerbations, mental health issues should be more systematically addressed enhancing benefit for the many not the few.

\section{Limitations}

Including nonrandomized studies and other reviews and meta-analyses resulted in differences to varying degrees from the typical intervention review. Reporting results in narratives impeded the drawing of statistical conclusions about the interventions' summary effect.

\section{Future needs}

Future research studies should focus on:

1. Identifying which components of PR are essential, its ideal length and location (hospital-based inpatient or outpatient, or community-based, home-based), the degree of supervision and intensity of training required, how long treatment effects persist, and the barriers of $\mathrm{PR}$ attendance and completion in real-life PR settings. 
2. Determining the best treatment for specific COPD groups, eg, based on sex, severity of COPD, frequency of exacerbations, and type and severity of comorbid mental health problems, so the efficacy of treatments in different subgroups can be assessed.

3. Disentangling the contributions of exercise training, education, and CBT in a COPD population with clear inclusion and exclusion criteria for anxiety and depression severity and adequately powered RCTs.

4. Investigate a range of treatment options in COPD across all care settings, including comparison of different treatment options and various combinations.

5. Address the cost-effectiveness and feasibility of targeted treatment of anxiety and depression, of the different interventions (eg, optimal length of therapy; when to stop treatment in nonresponders; identifying predictors of success and failure).

6. Examine novel types of disease management interventions with respect to social and behavioral principles and models most relevant for COPD patients in order to increase their engagement and improve health outcomes. ${ }^{247,248}$

7. Develop properly "evidence-based" COPD care programs that proactively address mental health in order to optimize physical and mental health outcomes.

\section{Conclusion}

Patients suffering from COPD frequently experience comorbid symptoms of anxiety and depression. Detection and recognition of these symptoms is of utmost importance as they are related to both disease progression, treatment, and rehabilitation procedures. Although the literature on treating anxiety and depression in COPD patients is limited, we believe that it points to a more multidisciplinary approach and to the implementation of personalized strategies to address both anxiety and depressive symptoms in these patients.

\section{Disclosure}

The authors report no conflicts of interest in this work.

\section{References}

1. Global Initiative for Chronic Obstructive Lung Disease. Global Strategy for the Diagnosis, Management, and Prevention of Chronic Obstructive Pulmonary Disease [Updated 2015]. Available from: http://www. goldcopd.org/. Accessed December 21, 2015.

2. National Heart Lung and Blood Institute. "What is COPD?" [Updated July 31, 2013]. Bethesda, MD: U.S. National Institutes of Health. Available from: http://www.nhlbi.nih.gov/health/health-topics/topics/copd. Accessed January 9, 2016.
3. Zwar NA, Marks GB, Hermiz O, et al. Predictors of accuracy of diagnosis of chronic obstructive pulmonary disease in general practice. Med J Aust. 2011;195(4):168-171.

4. Nathell L, Nathell M, Malmberg P, et al. COPD diagnosis related to different guidelines and spirometry techniques. Respir Res. 2007; 8(1):89.

5. Rabe KF, Hurd S, Anzueto A, et al. Global strategy for the diagnosis, management, and prevention of chronic obstructive pulmonary disease: GOLD executive summary. Am J Respir Crit Care Med. 2007;176(6): 532-555.

6. Lopez AD, Shibuya K, Rao C, et al. Chronic obstructive pulmonary disease: current burden and future projections. Eur Respir J. 2006;27: 397-412.

7. Mathers CD, Loncar D. Projections of global mortality and burden of disease from 2002 to 2030. PLoS Med. 2006;3:e442.

8. Edmunds M, Scudder L. Examining the relationships between COPD and anxiety and depression. Heart Lung. 2009;38:34-47.

9. Pooler A, Beech R. Examining the relationship between anxiety and depression and exacerbations of COPD which result in hospital admission: a systematic review. Int J Chron Obstruct Pulmon Dis. 2014;9: 315-330.

10. Yohannes AM, Baldwin RC, Connolly MJ. Depression and anxiety in elderly outpatients with chronic obstructive pulmonary disease: prevalence, and validation of the BASDEC screening questionnaire. Int J Geriatr Psychiatry. 2000;15:1090-1096.

11. Lacasse Y, Rousseau L, Maltais F. Prevalence of depressive symptoms and depression in patients with severe oxygen-dependent chronic obstructive pulmonary disease. J Cardiopulm Rehabil. 2001;21:80-86.

12. Aghanwa HS, Erhabor GE. Specific psychiatric morbidity among patients with chronic obstructive pulmonary disease in a Nigerian general hospital. J Psychosom Res. 2001;50:179-183.

13. Hill K, Geist R, Goldstein RS. Anxiety and depression in end-stage COPD. Eur Respir J. 2008;31(3):667-677.

14. Tselebis A, Bratis D, Pachi A, et al. Anxiety and depression in patients with chronic obstructive pulmonary disease (COPD). In: Zirimis L, Papazoglakis A, editors. Chronic Obstructive Pulmonary Disease: New Research. New York, NY: Nova Science Publishers; 2013:15-40. ISBN:978-1-62081-848.

15. Light RW, Merrill EJ, Despars JA, et al. Prevalence of depression and anxiety in patients with COPD: relationship to functional capacity. Chest. 1985;87:35-38.

16. Di Marco F, Verga M, Reggente M, et al. Anxiety and depression in COPD patients: the roles of gender and disease severity. Respir Med. 2006; 100:1767-1774.

17. Katz PP, Julian LJ, Omachi TA, et al. The impact of disability on depression among individuals with COPD. Chest. 2010;137:838-845.

18. McSweeny AJ, Grant I, Heaton RK, et al. Life quality of patients with chronic obstructive pulmonary disease. Arch Intern Med. 1982; 142(3):473-478.

19. Isoaho R, Keistinen T, Laippala $P$, et al. Chronic obstructive pulmonary disease and symptoms related to depression in elderly persons. Psychol Rep. 1995;76:287-297.

20. Borak J, Sliwinski P, Piasecki Z, et al. Psychological status of COPD patients on long term oxygen therapy. Eur Respir J. 1991;4:59-62.

21. Engstrom CP, Persson LO, Larsson S, et al. Functional status and well being in chronic obstructive pulmonary disease with regard to clinical parameters and smoking: a descriptive and comparative study. Thorax. 1996;51:825-830.

22. White RJ, Rudkin ST, Ashley J, et al. Outpatient pulmonary rehabilitation in severe chronic obstructive pulmonary disease. $J R$ Coll Physicians Lond. 1997;31:541-545.

23. Bosley CM, Corden ZM, Rees PJ, et al. Psychological factors associated with use of home nebulized therapy for COPD. Eur Respir J. 1996;9:2346-2350. 
24. Jones PW, Baveystock CM, Littlejohns P. Relationships between general health measured with the sickness impact profile and respiratory symptoms, physiological measures, and mood in patients with chronic airflow limitation. Am Rev Respir Dis. 1989;140:1538-1543.

25. Karajgi B, Rifkin A, Doddi S, et al. The prevalence of anxiety disorders in patients with chronic obstructive pulmonary disease. Am JPsychiatry. 1990;147:200-201.

26. Mikkelsen RL, Middelboe T, Pisinger C, et al. Anxiety and depression in patients with chronic obstructive pulmonary disease (COPD). A review. Nord J Psychiatry. 2004;58:65-70.

27. Dowson CA, Kuijer RG, Mulder RT. Anxiety and self-management behaviour in chronic obstructive pulmonary disease: what has been learned? Chron Respir Dis. 2004;1:213-220.

28. Hynninen KM, Breitve MH, Wiborg AB, et al. Psychological characteristics of patients with chronic obstructive pulmonary disease: a review. J Psychosom Res. 2005;59:429-443.

29. Maurer J, Rebbapragada V, Borson S, et al. Anxiety and depression in COPD: current understanding, unanswered questions, and research needs. Chest. 2008;134(4 Suppl):43S-56S.

30. Solano JP, Gomes B, Higginson IJ. A comparison of symptom prevalence in far advanced cancer, AIDS, heart disease, chronic obstructive pulmonary disease and renal disease. J Pain Symptom Manage. 2006;31: 58-69.

31. Felker B, Katon W, Hedrick SC, et al. The association between depressive symptoms and health status in patients with chronic pulmonary disease. Gen Hosp Psychiatry. 2001;23:56-61.

32. Yohannes AM, Baldwin RC, Connolly MJ. Depression and anxiety in elderly patients with chronic obstructive pulmonary disease. Age Ageing. 2006;35(5):457-459.

33. Hanania NA, Mullerova H, Locantore NW, et al. Determinants of depression in the ECLIPSE chronic obstructive pulmonary disease cohort. Am J Respir Crit Care Med. 2011;183:604-611.

34. Cully JA, Graham DP, Stanley MA, et al. Quality of life in patients with chronic obstructive pulmonary disease and comorbid anxiety or depression. Psychosomatics. 2006;47:312-319.

35. Prigatano GP, Wright EC, Levin D. Quality of life and its predictors in patients with mild hypoxemia and chronic obstructive pulmonary disease. Arch Intern Med. 1984;144(8):1613-1619.

36. Kosmas E, Tselebis A, Bratis D, et al. The Relationship between the adherence to treatment and the psychological profile of patients with chronic obstructive pulmonary disease. Chest. 2014; 145(3_MeetingAbstracts):377A.

37. Stapleton RD, Nielsen EL, Engelberg RA, et al. Association of depression and life-sustaining treatment preferences in patients with COPD. Chest. 2005;127:328-334.

38. Laurin C, Moullec G, Bacon SL, et al. Impact of anxiety and depression on chronic obstructive pulmonary disease exacerbation risk. Am J Respir Crit Care Med. 2012;185:918-923.

39. Fan VS, Curtis JR, Tu SP, et al. Using quality of life to predict hospitalization and mortality in patients with obstructive lung diseases. Chest. 2002;122:429-436.

40. Almagro P, Calbo E, de Echagüen AO, et al. Mortality after hospitalization for COPD. Chest. 2002;121:1441-1448.

41. Stage KB, Middelboe T, Pisinger C. Depression and chronic obstructive pulmonary disease (COPD). Impact on survival. Acta Psychiatr Scand. 2005;111(4):320-323.

42. Fan VS, Ramsey SD, Giardino ND, et al. Sex, depression, and risk of hospitalization and mortality in chronic obstructive pulmonary disease. Arch Intern Med. 2007;167:2345-2353.

43. American Psychiatric Association. Diagnostic and Statistical Manual of Mental Disorders. 4th ed. Washington, DC: APA; 1994.

44. World Health Organization. The ICD-10 Classification of Mental and Behavioural Disorders. Diagnostic Criteria for Research. Geneva, Switzerland: WHO; 1993

45. Hamilton M. The assessment of anxiety states by rating. $\mathrm{Br} \mathrm{J} \mathrm{Med}$ Psychol. 1959;32:50-55.
46. Beck AT, Epstein N, Brown G, Steer RA. An inventory for measuring clinical anxiety: psychometric properties. J Consult Clin Psychol. 1988;56:893-897.

47. Spielberger CD, Gorsuch RL, Lushene R, Vagg PR, Jacobs GA. Manual for the State-Trait Anxiety Inventory (Form Y). Palo Alto, CA: Consulting Psychologist's Press; 1983.

48. Willgoss TG, Yohannes AM. Anxiety disorders in patients with COPD: a systematic review. Respir Care. 2013;58(5):858-866.

49. Smoller JW, Pollack MH, Otto MW, et al. Panic anxiety, dyspnea, and respiratory disease. Theoretical and clinical considerations. Am J Respir Crit Care Med. 1996;154(1):6-17.

50. Klein DF. False suffocation alarms, spontaneous panics, and related conditions. An integrative hypothesis. Arch Gen Psychiatry. 1993;50:306-317

51. Dudley DL, Glaser EM, Jorgenson BN, et al. Psychosocial concomitants to rehabilitation in chronic obstructive pulmonary disease. Part 2: psychosocial treatment. Chest. 1980;77(4):544-551.

52. Kim HF, Kunik ME, Molinari VA, et al. Functional impairment in COPD patients: the impact of anxiety and depression. Psychosomatics. 2000;41:465-471

53. Pauwels RA, Buist AS, Calverley PMA, et al; GOLD Scientific Committee. Global strategy for the diagnosis, management, and prevention of chronic obstructive pulmonary disease. NHLBI/WHO Global Initiative for Chronic Obstructive Lung Disease (GOLD) Workshop summary. Am J Respir Crit Care Med. 2001;163:1256-1276.

54. Patton GC, Hibbert M, Rosier MJ, et al. Is smoking associated with depression and anxiety in teenagers? Am J Public Health. 1996; $86: 225-230$

55. Breslau N, Kilbey MM, Andreski P. Nicotine withdrawal symptoms and psychiatric disorders: findings from an epidemiologic study of young adults. Am J Psychiatry. 1992;149:464-469.

56. Acri JB, Grunberg N. A psychophysical task to quantify smoking cessation induced irritability: the reactive irritability scale (RIS). Addict Behav. 1992;17:587-601.

57. Parrott AC. Stress modulation over the day in cigarette smokers. Addiction. 1995;90:233-244.

58. Thornton A, Lee P, Fry J. Differences between smokers, ex-smokers, passive smokers and non-smokers. J Clin Epidemiol. 1994;47(10): 1143-1162.

59. Umezawa A. A respiratory control method based on psycho-physiological studies. Proceedings of the 11th Annual Meeting of the International Society for the Advancement of Respiratory Psychophysiology (ISARP), Princeton NJ, October 17-19, 2004. Biol Psychiatry. 2006;(72):222-238.

60. O’Donnell D, Banzett R, Carrieri-Kohlman V, et al. Pathophysiology of dyspnea in chronic obstructive pulmonary disease: a roundtable. Proc Am Thorac Soc. 2007;4:145-168.

61. Jolley CJ, Moxham J. A physiological model of patient-reported breathlessness during daily activities in COPD. Eur Respir Rev. 2009; 18(112):66-79.

62. Liotti M, Brannan S, Egan G, et al. Brain responses associated with consciousness of breathlessness (air hunger). Proc Natl Acad Sci US A. 2001;98:2035-2040.

63. Evans KC, Banzett RB, Adams L, et al. BOLD fMRI identifies limbic, paralimbic, and cerebellar activation during air hunger. J Neurophysiol. 2002;88:1500-1511.

64. Livermore N, Butler J, Sharpe L, McBain R, Gandevia S, McKenzie D. Panic attacks and perception of inspiratory resistive loads in chronic obstructive pulmonary disease. Am J Respir Crit Care Med. 2008; 178:7-12.

65. Bailey PH. The dyspnea-anxiety-dyspnea cycle - COPD patients' stories of breathlessness: "It's scary/when you can't breathe". Qual Health Res. 2005;14(6):760-778.

66. Porzelius J, Vest M, Nochomovitz M. Respiratory function, cognitions, and panic in chronic obstructive pulmonary patients. Behav Res Ther. 1992;30:75-77. 
67. Howard C, Hallas C, Wray J, et al. The relationship between illness perceptions and panic in chronic obstructive pulmonary disease. Behav Res Ther. 2009;47:71-76.

68. McKenzie D, Butler J, Gandevia S. Respiratory muscle function and activation in chronic obstructive pulmonary disease. J Appl Physiol. 2009;107:621-629.

69. Vanderpool M. Resilience: a missing link in our understanding of survival. Harv Rev Psychiatry. 2002;10:302-306.

70. Dowson CA, Town GI, Framptom C, et al. Psychopathology and illness beliefs influence COPD self-management. J Psychosom Res. 2004;56(3):333-340

71. O'Donnell DE, Webb K, McGuire M. Controlling Breathlessness and Cough. Comprehensive Management of COPD. Hamilton, ON: B.C. Decker; 2002.

72. Lustig FM, Haas A, Castillo R. Clinical and rehabilitation regime in patients with chronic obstructive pulmonary diseases. Arch Phys Med Rehabil. 1972;53:315-322.

73. Cantor L, Jacobson R. COPD: how to manage comorbid depression and anxiety. J Fam Pract. 2003;2:11.

74. Brown GW, Andrews B, Harris T, Adler Z, Bridge L. Social support, self esteem and depression. Psychol Med. 1986;6:238-247.

75. Holahan CK, Holahan CJ. Self-efficacy, social support, and depression in aging: a longitudinal analysis. J Gerontol. 1987;42(1):65-68.

76. Kaptein AA, Scharloo M, Fischer MJ, et al. Illness perceptions and COPD: an emerging field for COPD patient management. J Asthma. 2008;45:625-629.

77. Tselebis A, Kosmas E, Bratis D, et al. Prevalence of alexithymia and its association with anxiety and depression in a sample of Greek chronic obstructive pulmonary disease (COPD) outpatients. Ann Gen Psychiatry. 2010;9:16.

78. Mishima M, Oku Y, Muro S, et al. Relationship between dyspnoea in daily life and psycho-physiologic state in patients with chronic obstructive pulmonary disease during long term domiciliary oxygen therapy. Intern Med. 1996;35:453-458.

79. American Psychiatric Association. Diagnostic and Statistical Manual of Mental Disorders. 5th ed. Washington, DC: APA; 2015.

80. Gift AG, McCrone SH. Depression in patients with COPD. Heart Lung 1993;22:289-297.

81. Koenig HG. Differences between depressed patients with heart failure and those with pulmonary disease. Am J Geriatr Psychiatry. 2006;14: 211-219.

82. Kurosawa H, Shimizu Y, Nishimatsu Y, et al. The relationship between mental disorders and physical severities in patients with acute myocardial infarction. Jpn Circ J. 1983;47(6):723-728.

83. Katon W, Sullivan MD. Depression and chronic medical illness. J Clin Psychiatry. 1990;51:3-11.

84. Evans DL, Staab JP, Petitto JM, et al. Depression in the medical setting: biopsychological interactions and treatment considerations. J Clin Psychiatry. 1999;60(Suppl 4):40-55.

85. Yohannes AM, Baldwin RC, Connolly MJ. Prevalence of sub-threshold depression in elderly patients with chronic obstructive pulmonary disease. Int J Geriatr Psychiatry. 2003;18:412-416.

86. Emery CF, Green MR, Suh S. Neuropsychiatric function in chronic lung disease: the role of pulmonary rehabilitation. Respir Care. 2008;53(9):1208-1216.

87. Graydon JE, Ross E. Influence of symptoms, lung function, mood, and social support on level of functioning of patients with COPD. Res Nurs Health. 1995;18(6):525-533.

88. Weaver TE, Richmond TS, Narsavage GL. An explanatory model of functional status in chronic obstructive pulmonary disease. Nurs Res. 1997;46(1):26-31.

89. Johnson G, Kong DC, Thoman R. Factors associated with medication nonadherence in patients with COPD. Chest. 2005;128(5): 3198-3204.

90. Leidy NK. Functional performance in people with chronic obstructive pulmonary disease. Image J Nurs Sch. 1995;27(1):23-34.
91. Wagena EJ, Kant I, Huibers MJ, et al. Psychological distress and depressed mood in employees with asthma, chronic bronchitis or emphysema: a population-based observational study on prevalence and the relationship with smoking cigarettes. Eur J Epidemiol. 2004;19(2):147-153.

92. Post L, Collins C. The poorly coping COPD patient: a psychotherapeutic perspective. Int J Psychiatry Med. 1981-1982;11(2):173-182.

93. Cleland JA, Lee AJ, Hall S. Associations of depression and anxiety with gender, age, health-related quality of life and symptoms in primary care COPD patients. Fam Pract. 2007;24(3):217-223.

94. Norwood RJ. A review of etiologies of depression in COPD. Int J Chron Obstruct Pulmon Dis. 2007;2(4):485-491.

95. Schmidt NB, Telch MJ, Jaimez TL. Biological challenge manipulation of PCO2 levels: a test of Klein's (1993) suffocation alarm theory of panic. J Abnorm Psychol. 1996;105(3):446-454.

96. Ferguson DM. Comorbidity between depressive disorders and nicotine dependence in a cohort of 16 year olds. Arch Gen Psychiatry. 1996;53:1043-1047.

97. Agle DP, Baum GL. Psychological aspects of chronic obstructive pulmonary disease. Med Clin North Am. 1977;61(4):749-758.

98. Dunlop DD, Lyons JS, Manheim LM, et al. Arthritis and heart disease as risk factors for major depression: the role of functional limitation. Med Care. 2004;42(6):502-511.

99. Cooper CB. Determining the role of exercise in patients with chronic pulmonary disease. Med Sci Sports Exerc. 1995;27:147-157.

100. van Dijk EJ, Vermeer SE, de Groot JC, et al. Arterial oxygen saturation, COPD, and cerebral small vessel disease. J Neurol Neurosurg Psychiatry. 2004;75:733-736.

101. Campbell JJ 3rd, Coffey CE. Neuropsychiatric significance of subcortical hyperintensity. J Neuropsychiatry Clin Neurosci. 2001;13: 261-288.

102. El-Ad B, Lavie P. Effect of sleep apnea on cognition and mood. Int Rev Psychiatry. 2005;17(4):277-282.

103. Ozge C, Ozge A, Unal O. Cognitive and functional deterioration in patients with severe COPD. Behav Neurol. 2006;17(2):121-130.

104. Aloia MS, Arnedt JT, Davis JD, et al. Neuropsychological sequelae of obstructive sleep apnea-hypopnea syndrome: a critical review. J Int Neuropsychol Soc. 2004;10:772-785.

105. Figiel GS, Krishnan KR, Doraiswamy PM, et al. Subcortical hyperintensities on brain magnetic resonance imaging: a comparison between late age onset and early onset elderly depressed subjects. Neurobiol Aging. 1991;12:245-247.

106. Barnes PJ, Celli BR. Systemic manifestations and comorbidities of COPD. Eur Respir J. 2009;33:1165-1185.

107. Nussbaumer-Ochsner Y, Rabe KF. Systemic manifestations of COPD. Chest. 2011;139(1):165-173.

108. Eagan TM, Ueland T, Wagner PD, et al. Systemic inflammatory markers in COPD: results from the Bergen COPD Cohort Study. Eur Respir J. 2010;35:540-548.

109. Anisman H, Merali Z, Hayley S. Neurotransmitter, peptide and cytokine processes in relation to depressive disorder: comorbidity between depression and neurodegenerative disorders. Prog Neurobiol. 2008; 85:1-74.

110. Bemt L, Schermer T, Bor H. The risk for depression comorbidity in patients with COPD. Chest. 2009;135(1):108-111.

111. Gift AG, Wood RM, Cahill CA. Depression, somatization and steroid use in chronic obstructive pulmonary disease. Int J Nurs Stud. 1989;26:281-286.

112. Cafarella PA, Effing TW, Usmani ZA. Treatments for anxiety and depression in patients with chronic obstructive pulmonary disease: a literature review. Respirology. 2012;17(4):627-638.

113. National Institute for Health and Care Excellence. Depression in Adults with a Chronic Physical Health Problem. Treatment and Management. London, UK: National Institute for Health and Care Excellence; 2009. Available from: http://www.nice.org.uk/guidance/cg91. Accessed December 21, 2015. 
114. da Costa Santos CM, de Mattos Pimenta CA, Nobre MR. The PICO strategy for the research question construction and evidence search. Rev Lat Am Enfermagem. 2007;15(3):508-511.

115. O'Connor D, Green S, Higgins JPT. Defining the review question and developing criteria for including studies. In: Higgins JPT, Green S, editors. Cochrane Handbook for Systematic Reviews of Interventions, Version 5.0.0 [Updated February 2008]. London, UK: The Cochrane Collaboration. Available from: http://www.cochrane-handbook.org/. Accessed December 21, 2015.

116. Critical Appraisal Skills Programme. Critical Appraisal Skills Programme: Making Sense Of Evidence. Secondary Critical Appraisal Skills Programme: Making Sense Of Evidence. 2013. Available from: http://www.casp-uk.net/. Accessed December 21, 2015.

117. National Institute for Health and Clinical Excellence. Depression. The treatment and management of depression in adults. This is a partial update of NICE clinical guideline 23. NICE clinical guideline 90. October 2009. Available from: https://www.nice.org.uk/guidance/ cg90. Accessed January 9, 2016.

118. Yohannes AM. Management of anxiety and depression in patients with COPD. Expert Rev Respir Med. 2008;2:337-347.

119. Xu W, Collet JP, Shapiro S, et al. Independent effect of depression and anxiety on chronic obstructive pulmonary disease exacerbations and hospitalizations. Am J Respir Crit Care Med. 2008;178:913-920.

120. Koenig HG. Predictors of depression outcomes in medical inpatients with chronic pulmonary disease. Am J Geriatr Psychiatry. 2006;14: 939-948.

121. Kunik ME, Roundy K, Veazey C, et al. Surprisingly high prevalence of anxiety and depression in chronic breathing disorders. Chest. 2005; 127:1205-1211.

122. Cicutto LC, Brooks D. Self-care approaches to managing chronic obstructive pulmonary disease: a provincial survey. Respir Med. 2006;100:1540-1546.

123. Covino NA, Dirks JF, Kinsman RA, et al. Patterns of depression in chronic illness. Psychother Psychosom. 1982;37:144-153.

124. Coffey CE, Figiel GS, Djang WT, et al. Leukoencephalopathy in elderly depressed patients referred for ECT. Biol Psychiatry. 1988;24: 143-161.

125. Hickie I, Scott E, Mitchell P, et al. Subcortical hyperintensities on magnetic resonance imaging: clinical correlates and prognostic significance in patients with severe depression. Biol Psychiatry. 1995;37:151-160.

126. Krishnan KR, Hays JC, Tupler LA, et al. Clinical and phenomenological comparisons of late-onset and early-onset depression. Am J Psychiatry. 1995;152:785-788.

127. Krishnan KR, Hays JC, Blazer DG. MRI-defined vascular depression. Am J Psychiatry. 1997;154:497-501.

128. Fujikawa T, Yamawaki S, Touhouda Y. Background factors and clinical symptoms of major depression with silent cerebral infarction. Stroke. 1994;25:798-801.

129. Covey LS, Glassman AH, Stetner F. Major depression following smoking cessation. Am J Psychiatry. 1997;154(2):263-265.

130. Covey LS. Tobacco cessation among patients with depression. Prim Care. 1999;26(3):691-706.

131. Hillas G, Perlikos F, Tsiligianni I, et al. Managing comorbidities in COPD. International Journal of COPD. 2015;10:95-109.

132. Nelson DR. The cytochrome p450 homepage. Hum Genomics. 2009; $4: 59-65$.

133. Steen SN. The effects of psychotropic drugs on respiration. Pharmacol Ther B. 1976;2:717-741

134. Man GCW, Hsu K, Spoule BJ, et al. Effect of alprazolam on exercise and dyspnea in patients with chronic obstructive pulmonary disease. Chest. 1986;90:832-836.

135. Halvorsen T, Martinussen PE. Benzodiazepine use in COPD: empirical evidence from Norway. Int J Chron Obstruct Pulmon Dis. 2015;10:1695-1702

136. Ekström MP, Bornefalk-Hermansson A, Abernethy AP, et al. Safety of benzodiazepines and opioids in very severe respiratory disease: national prospective study. BMJ. 2014;348:g445.
137. Borson S, McDonald GJ, Gayle T, et al. Improvement in mood, physical symptoms, and function with nortriptyline for depression in patients with chronic obstructive pulmonary disease. Psychosomatics. 1992;33:190-201.

138. Light RW, Merrill EJ, Despars J, et al. Doxepin treatment of depressed patients with chronic obstructive pulmonary disease. Arch Intern Med. 1986;146:1377-1380.

139. Ström K, Boman G, Pehrsson K, et al. Effect of protriptyline, $10 \mathrm{mg}$ daily, on chronic hypoxaemia in chronic obstructive pulmonary disease. Eur Respir J. 1995;8:425-429.

140. Gordon GH, Michiels TM, Mahutte CK, et al. Effect of desipramine on control of ventilation and depression scores in patients with severe chronic obstructive pulmonary disease. Psychiatry Res. 1985; 15:25-32.

141. Sharma TN, Goyal RL, Gupta PR, et al. Psychiatric disorders in COPD with special reference to the usefulness of imipramine-diazepam combination. Indian J Chest Dis Allied Sci. 1988;30:263-268.

142. Borson S, Claypoole K, McDonald GL. Depression and chronic obstructive pulmonary disease: treatment trials. Semin Clin Neuropsychiatry. 1998;3:115-130.

143. Yohannes AM, Connolly MJ, Baldwin RC. A feasibility study of antidepressant drug therapy in depressed elderly patients with chronic obstructive pulmonary disease. Int J Geriatr Psychiatry. 2001;16: 451-454.

144. Eiser N, Harte R, Spiros K. Effect of treating depression on qualityof-life and exercise tolerance in severe COPD. COPD. 2005;2: 233-241.

145. Papp LA, Weiss JR, Greenberg HE, et al. Sertraline for chronic obstructive pulmonary disease and comorbid anxiety and mood disorders. Am J Psychiatry. 1995;152:1531.

146. Smoller JW, Pollack MH, Systrom D, et al. Sertraline effects on dyspnea in patients with obstructive airways disease. Psychosomatics. 1998; 39:24-29.

147. Lacasse Y, Beaudoin L, Rousseau L, et al. Randomized trial of paroxetine in end-stage COPD. Monaldi Arch Chest Dis. 2004;61:140-147.

148. Evans M, Hammond M, Wilson K, et al. Placebo controlled treatment trial of depression in elderly physically ill patients. Int J Geriatr Psychiatry.1997;12:817-824.

149. Silvertooth EJ, Doraiswamy PM, Clary GL, et al. Citalopram and quality of life in lung transplant recipients. Psychosomatics. 2004; 45:171-272.

150. Hegerl U, Mergl R. Depression and suicidality in COPD: understandable reaction or independent disorders? Eur Respir J. 2014;44(3):734-743.

151. Voekel M, Voelkel NF, MacNee W. Chronic Obstructive Lung Diseases 2. Psychosocial Aspects of Chronic Obstructive Pulmonary Disease. Hamilton, ON: B.C. Decker Inc; 2008.

152. Brenes GA. Anxiety and chronic obstructive pulmonary disease: prevalence, impact, and treatment. Psychosom Med. 2003;65:963-970.

153. Argyropoulou P, Patakas D, Koukou A, et al. Buspirone effect on breathlessness and exercise performance in patients with chronic obstructive pulmonary disease. Respiration. 1993;60:216-220.

154. Singh NP, Despars JA, Stansbury DW, et al. Effects of buspirone on anxiety levels and exercise tolerance in patients with chronic airflow obstruction and mild anxiety. Chest. 1993;103:800-804.

155. Usmani ZA, Carson KV, Cheng J, et al. Pharmacological interventions for the treatment of anxiety disorders in chronic obstructive pulmonary disease (Review). Cochrane Database Syst Rev. 2011;(11):CD008483.

156. Subbe C, Collier GM, Bedson E, et al. ISRCTN41544517: Pilot Study to Examine the Effect of Citalopram on Health Status, Anxiety and Depression in Patients with Chronic Obstructive Pulmonary Disease. 2004. Available from: www.controlled-trials.com. Accessed December 21, 2015.

157. Yohannes AM, Connolly MJ. Do antidepressants work in patients with chronic obstructive pulmonary disease with comorbid depression? Expert Rev Respir Med. 2011;5(6):727-729. 
158. Wilson I. Depression in the patient with COPD. Int J Chron Obstruct Pulmon Dis. 2006;1(1):61-64.

159. Yohannes AM, Alexopoulos GS. Pharmacologic treatment of depression in older patients with COPD: impact on the course of the disease and health outcomes. Drugs Aging. 2014;31(7):483-492.

160. Bourbeau J, Nault D, Borycki E. Comprehensive Management of Chronic Obstructive Pulmonary Disease. Hamilton, ON: B.C. Decker Inc; 2002.

161. McHugh RK, Whitton SW, Peckham AD, et al. Patient preference for psychological vs pharmacologic treatment of psychiatric disorders: a meta-analytic review. J Clin Psychiatry. 2013;74(6):595-602.

162. National Institute for Health and Clinical Excellence. NICE Clinical Guideline 22 Anxiety (Amended): Management of Anxiety (Panic Disorder, With or Without Agoraphobia, and Generalized Anxiety Disorder) in Adults in Primary, Secondary or Community Care. London, UK: National Institute for Health and Clinical Excellence; 2007. Available from: https://www.nice.org.uk/guidance/cg22. Accessed January 9, 2016.

163. National Institute for Health and Clinical Excellence. CG91 Depression with a Chronic Physical Health Problem: NICE Guideline. London, UK: National Collaborating Centre for Mental Health; 2009. Available from: https://www.nice.org.uk/guidance/cg91. Accessed January 9, 2016.

164. Beck AT, Rush AJ, Shaw BF, et al. Cognitive Therapy for Depression. New York, NY: Guildford Press; 1979.

165. Heslop K, De Soyza A, Baker CR, Stenton C, Burns GP. Using individualized cognitive behavioral therapy as a treatment for people with COPD. Nurs Times. 2009;105:14-17.

166. Kraus CA, Kunik ME, Stanley MA. Use of cognitive behavioral therapy in late-life psychiatric disorders. Geriatrics. 2007;62:21-26.

167. Lightner E. Effect of individual cognitive behavioral therapy on depression and anxiety in older adults with chronic obstructive pulmonary disease: a feasibility study. Psychology Dissertations. 2010; Paper 81. Available from: http://digitalcommons.pcom.edu/psychology_dissertations/81. Accessed December 21, 2015.

168. Ekers D, Richards D, Gilbody S. A meta-analysis of randomized trials of behavioural treatment of depression. Psychol Med. 2008; 38:611-623.

169. Hynninen M, Bjerke N, Pallesen S, et al. A randomized controlled trial of cognitive behavioral therapy for anxiety and depression in COPD. Respir Med. 2010;104:986-994.

170. Kunik ME, Braun U, Stanley MA, et al. One session cognitive behavioural therapy for elderly patients with chronic obstructive pulmonary disease. Psychol Med. 2001;31:717-723.

171. Smith SMS, Sonego S, Ketcheson L, et al. A review of the effectiveness of psychological interventions used for anxiety and depression in chronic obstructive pulmonary disease. BMJ Open Respir Res. 2014;1:e00042.

172. Coventry PA, Gellatly JL. Improving outcomes for COPD patients with mild-to-moderate anxiety and depression: a systematic review of cognitive behavioural therapy. Br J Health Psychol. 2008;13: 381-400.

173. Yalom ID, Leszcz M. The Theory and Practice of Group Psychotherapy. 5th ed. New York, NY: Basic Books; 2005: XII.

174. Butler T, Fuhriman A. Curative factors in group therapy: a review of the recent literature. Small Group Res. 1983;14:131-142.

175. Vickers A, Zollman C. ABC of complementary medicine. Hypnosis and relaxation therapies. BMJ. 1999;319:1346-1349.

176. Volpato E, Banfi P, Roger SM, et al. Relaxation techniques for people with chronic obstructive pulmonary disease: a systematic review and a meta-analysis. Evid Based Complement Alternat Med. 2015;2015:628365.

177. Benson H, Beary JF, Carol MP. The relaxation response. Psychiatry. 1974;37:37-46.

178. Devine EC, Pearcy J. Meta-analysis of the effects of psychoeducational care in adults with chronic obstructive pulmonary disease. Patient Educ Couns. 1996;29:167-178.
179. Lolak S, Connors GL, Sheridan MJ, et al. Effects of progressive muscle relaxation training on anxiety and depression in patients enrolled in an outpatient pulmonary rehabilitation program. Psychother Psychosom. 2008;77:119-125.

180. Yeh GY, Roberts DH, Wayne PM, et al. Tai chi exercise for patients with chronic obstructive pulmonary disease: a pilot study. Respir Care. 2010;55:1475-1482.

181. Donesky-Cuenco D, Nguyen HQ, Paul S, et al. Yoga therapy decreases dyspnea-related distress and improves functional performance in people with chronic obstructive pulmonary disease: a pilot study. J Altern Complement Med. 2009;15:225-234.

182. Lord VM, Cave P, Hume VJ, et al. Singing teaching as a therapy for chronic respiratory disease - a randomised controlled trial and qualitative evaluation. BMC Pulm Med. 2010;10:41.

183. Lord VM, Hume VJ, Kelly JL, et al. Singing classes for chronic obstructive pulmonary disease: a randomized controlled trial. BMC Pulm Med. 2012;12:69.

184. Bonilha AG, Onofre F, Vieira ML, et al. Effects of singing classes on pulmonary function and quality of life of COPD patients. Int $J$ Chron Obstruct Pulmon Dis. 2009;4:1-8.

185. Pumar MI, Gray CR, Walsh JR, et al. Anxiety and depression important psychological comorbidities of COPD. J Thorac Dis. 2014; 6(11):1615-1631.

186. Nici L, Donner C, Wouters E, et al; ATS/ERS Pulmonary Rehabilitation Writing Committee. American Thoracic Society/European Respiratory Society statement on pulmonary rehabilitation. Am J Respir Crit Care Med. 2006;173:1390-1414.

187. Richard Z. The nonpharmacologic treatment of chronic obstructive pulmonary disease. Advances in our understanding of pulmonary rehabilitation. Proc Am Thorac Soc. 2007;4(7):549-553.

188. Stockley RA. Chronic Obstructive Pulmonary Disease. Oxford, UK: Blackwell Publishing Ltd; 2007.

189. Spruit MA, Singh SJ, Garvey C, et al. An official American Thoracic Society/European Respiratory Society statement: key concepts and advances in pulmonary rehabilitation. Am J Respir Crit Care Med. 2013;188(8):1011-1027.

190. Goldstein RS, Gort EH, Stubbing D, et al. Randomised controlled trial of respiratory rehabilitation. Lancet. 1994;344:1394-1397.

191. Griffiths TL, Burr ML, Campbell IA, et al. Results at 1 year of outpatient multidisciplinary pulmonary rehabilitation: a randomised controlled trial. Lancet. 2000;355:362-368.

192. Mota S, Güell R, Barreiro E, et al. Clinical outcomes of expiratory muscle training in severe COPD patients. Respir Med. 2007; 101(3):516-524.

193. Emery CF, Shermer RL, Hauck ER, et al. Cognitive and psychological outcomes of exercise in a 1-year follow-up study of patients with chronic obstructive pulmonary disease. Health Psychol. 2003;22:598-604.

194. Kozora E, Tran ZV, Make B. Neurobehavioral improvement after brief rehabilitation in patients with chronic obstructive pulmonary disease. J Cardiopulm Rehabil. 2002;22:426-430.

195. Garuti G, Cilione C, Dell'Orso D, et al. Impact of comprehensive pulmonary rehabilitation on anxiety and depression in hospitalized COPD patients. Monaldi Arch Chest Dis. 2003;59:56-61.

196. Boutou AK, Tanner RJ, Lord VM, et al. An evaluation of factors associated with completion and benefit from pulmonary rehabilitation in COPD. BMJ Open Respir Res. 2014;1:e000051.

197. Fischer MJ, Scharloo M, Abbink JJ, et al. Participation and drop-out in pulmonary rehabilitation: a qualitative analysis of the patient's perspective. Clin Rehabil. 2007;21:212-221.

198. Robertson N. Running up that hill: how pulmonary rehabilitation can be enhanced by understanding patient perceptions of their condition. Chron Respir Dis. 2010;7(4):203-205.

199. Dishman RK. Brain monoamines, exercise, and behavioral stress: animal models. Med Sci Sports Exerc. 1997;29(1):63-74.

200. Ransford CP. A role for amines in the antidepressant effect of exercise: a review. Med Sci Sports Exerc. 1982;14(1):1-10. 
201. Dunn AL, Reigle TG, Youngstedt SD, et al. Brain norepinephrine and metabolites after treadmill training and wheel running in rats. Med Sci Sports Exerc. 1996;28(2):204-209.

202. Jacobs BL. Serotonin, motor activity and depression-related disorders. Am Sci. 1994;82:456-463.

203. Chaouloff F. Effects of acute exercise on central serotonergic systems. Med Sci Sports Exerc. 1997;29(1):58-62.

204. Raglin JS, Morgan WP. Influence of exercise and quiet rest on state anxiety and blood pressure. Med Sci Sports Exerc. 1981;19(5):456-463.

205. Carr DB, Bullen BA, Skrinar GS, et al. Physical conditioning facilitates the exercise-induced secretion of beta-endorphin and beta-lipotropin in women. N Engl J Med. 1981;305(10):597-617.

206. Farrell PA, Gates WK, Maksud MG, et al. Increases in plasma beta-endorphin/beta-lipotropin immunoreactivity after treadmill running in humans. J Appl Physiol Respir Environ Exerc Physiol. 1982;52(5):1245-1249.

207. Gambert SR, Hagen TC, Garthwaite TL. Exercise and the endogenous opioids. N Engl J Med. 1981;305:1590-1591.

208. Pitsavos C, Chrysohoou C, Panagiotakos DB, et al. Association of leisure-time physical activity on inflammation markers (C-reactive protein, white cell blood count, serum amyloid $\mathrm{A}$, and fibrinogen) in healthy subjects (from the ATTICA study). Am J Cardiol. 2003;91(3): 368-370.

209. Church TS, Barlow CE, Earnest CP, et al. Associations between cardiorespiratory fitness and C-reactive protein in men. Arterioscler Thomb Vasc Biol. 2002;22(11):1869-1876.

210. Morrow J, Nolen-Hoeksema S. Effects of response to depression on the remediation of depressive affect. J Pers Soc Psychol. 1990; 58(3):519-527.

211. Nolen-Hoeksema S, Morrow J. A prospective study of depression and posttraumatic stress symptoms after a natural disaster: the 1989 Loma Prieta earthquake. J Pers Soc Psychol. 1991;61(1):115-121.

212. McAuley E, Jerome GJ, Marquez DX, et al. Exercise self-efficacy in older adults: social, affective, and behavioral influences. Ann Behav Med. 2003;25(1):1-7.

213. Craft LL. Exercise and clinical depression: examining two psychological mechanisms. Psychol Sport Exerc. 2003;6:151-171.

214. Lewinsohn PM, Gotlib IH. Behavioral theory and treatment of depression. In: Beckham EE, Leber WR, editors. Handbook of Depression. 2nd ed. New York, NY: Guildford Press; 1995:352-375.

215. Bartoholomew JB, Ciccolo JT. Exercise, depression, and cognition. In: Spirduso WW, Poon LW, Chodzko-Zajko W, editors. Exercise and Its Mediating Effects on Cognition. Vol. 2. Champaign, IL: Human Kinetics; 2008:33-46.

216. Coventry PA, Hind D. Comprehensive pulmonary rehabilitation for anxiety and depression in adults with chronic obstructive pulmonary disease: systematic review and meta-analysis. J Psychosom Res. 2007;63:551-565.

217. Withers NJ, Rudkin ST, White RJ. Anxiety and Depression in Sever Chronic Obstructive Pulmonary Disease: The Effects of Pulmonary Rehabilitation. Bristol, UK: Department of Medicine, Frenchay Hospital; 1999.

218. Alexopoulos GS, Kiosses DN, Sirey JA, et al. Untangling therapeutic ingredients of a personalized intervention for patients with depression and severe COPD. Am J Geriatr Psychiatry. 2014; 22(11):1316-1324.

219. Ries AL, Kaplan RM, Limberg TM, et al. Effects of pulmonary rehabilitation on physiologic and psychosocial outcomes in patients with chronic obstructive pulmonary disease. Ann Intern Med. 1995; 122:823-832.

220. Sassi-Dambron DE, Eakin EG, Ries AL, et al. Treatment of dyspnea in COPD: a controlled clinical trial of dyspnea management strategies. Chest. 1995;107:724-729.

221. Lorig KR, Sobel DS, Stewart AL, et al. Evidence suggesting that a chronic disease self-management program can improve health status while reducing hospitalization: a randomized trial. Med Care. 1999;37:5-14.
222. Pantou I, Harikiopoulou M, Bratis D, et al. The impact of rehabilitationinduced symptomatic, functional and psychological outcomes on health-related quality of life. European Respiratory Society, Annual Congress. September $2-6,2006$, Munich, Germany. Published in European Respiratory Journal, 2006;28(suppl 5).

223. Paz-Diaz H, Montes de Oca M, Lopez JM, et al. Pulmonary rehabilitation improves depression, anxiety, dyspnea and health status in patients with COPD. Am J Phys Med Rehabil. 2006;86(1):30-35.

224. Jácome C, Marque A. Impact of pulmonary rehabilitation in subjects with mild COPD. Respir Care. 2014;59(10):1577-1582.

225. Alexopoulos GS, Sirey JA, Raue PJ, et al. Outcomes of depressed patients undergoing inpatient pulmonary rehabilitation. Am J Geriatr Psychiatry. 2006;14:466-475.

226. Guell R, Resqueti V, Sangenis M, et al. Impact of pulmonary rehabilitation on psychosocial morbidity in patients with severe COPD. Chest. 2006;129:899-904.

227. Kosmas E, Tselebis A, Bratis D, et al. Impact of pulmonary rehabilitation on anxiety and depression in patients with COPD. European Respiratory Society, Annual Congress. 2008, Berlin, Germany.

228. Pantou I, Harikiopoulou M, Mpletsa M, et al. Does the severity of chronic obstructive pulmonary disease reflect on the outcomes of pulmonary rehabilitation? European Respiratory Society, Annual Congress. Stockholm. 2007.

229. Mignogna J, Cully JA. Depression and anxiety in patients with COPD: a focus on psychological treatments in ambulatory care settings. Curr Respir Med Rev. 2012;8:137-144.

230. Panagioti M, Scott C, Blakemor A, et al. Overview of the prevalence, impact, and management of depression and anxiety in chronic obstructive pulmonary disease. Int J Chron Obstruct Pulmon Dis. 2014;9:1289-1306.

231. Yohannes AM, Alexopoulos GS. Depression and anxiety in patients with COPD. Eur Respir Rev. 2014;23(133):345-349.

232. U.S. Preventive Services Task Force. Screening for depression: recommendations and rationale. Ann Intern Med. 2002;136:760-764.

233. Gilbody S, House AO, Sheldon TA. Screening and case finding instruments for depression. Cochrane Database Syst Rev. 2005;(4): CD002792.

234. Cavanaugh S, Clark DC, Gibbons RD. Diagnosing depression in the hospitalized medically ill. Psychosomatics. 1983;24:809-815.

235. Bukberg J, Penman D, Holland JC. Depression in hospitalized cancer patients. Psychosom Med. 1984;46:199-212.

236. Endicott J. Measurement of depression in patients with cancer. Cancer. 1984;53:2243-2249.

237. Yates WR, Mitchell J, Rush AJ, et al. Clinical features of depressed outpatients with and without co-occurring general medical conditions in STAR*D. Gen Hosp Psychiatry. 2004;26:421-429.

238. Yohannes AM, Willgoss TG, Baldwin RC, Connolly MJ. Depression and anxiety in chronic heart failure and chronic obstructive pulmonary disease: prevalence, relevance, clinical implications and management principles. Int J Geriatr Psychiatry. 2010;25:1209-1221.

239. Simon GE, Von Korff M. Medical co-morbidity and validity of DSM-IV depression criteria. Psychol Med. 2006;36:27-36.

240. Engstrom CP, Persson LO, Larsso S, et al. Health-related quality of life in COPD: why both disease-specific and generic measures should be used. Eur Respir J. 2001;18:69-76.

241. Alexopoulos GS, Raue PJ, Sirey JA, Arean PA. Developing an intervention for depressed, chronically medically ill elders: a model from COPD. Int J Geriatr Psychiatry. 2008;23(5):447-453.

242. Alexopoulos GS, Kiosses DN, Sirey JA, et al. Personalised intervention for people with depression and severe COPD. Br J Psychiatry. 2013;202(3):235-236

243. Gilbody S, Bower P, Fletcher J, et al. Collaborative care for depression: a cumulative meta-analysis and review of longer-term outcomes. Arch Intern Med. 2006;166:2314-2321.

244. Archer J, Bower P, Gilbody S, et al. Collaborative care for depression and anxiety problems. Cochrane Database Syst Rev. 2012;10: CD006525. 
245. Katon WJ, Lin EH, Von Korff M, et al. Collaborative care for patients with depression and chronic illnesses. $N$ Engl J Med. 2010;363(27): 2611-2620.

246. Coventry PA, Bower P, Keywort C, et al. The effect of complex interventions on depression and anxiety in chronic obstructive pulmonary disease: systematic review and meta-analysis. PLoS One. 2013;8(4):e60532.

247. Clark NM, Dodge JA, Partridge MR, et al. Focusing on outcomes: making the most of COPD interventions. Int JChron Obstruct Pulmon Dis. 2009;4:61-77.

248. Almagro P, Castro A. Helping COPD patients change health behavior in order to improve their quality of life. Int J Chron Obstruct Pulmon Dis. 2013;8:335-345.

249. Momtaz OM, Rabei SM, Tawfike NR, et al. Effect of treatment of depression and anxiety on physiological state of severe COPD patients. Egypt J Chest Dis Tuberc. 2015;64:29-34.

250. He Y, Zheng Y, Xu C, et al. Sertraline hydrochloride treatment for patients with stable chronic obstructive pulmonary disease complicated with depression: a randomized controlled trial. Clin Respir J. Epub October 13, 2014.

251. Bove DG, Overgaard D, Lomborg K, et al. Efficacy of a minimal home-based psychoeducative intervention versus usual care for managing anxiety and dyspnoea in patients with severe chronic obstructive pulmonary disease: a randomised controlled trial protocol BMJ Open. 2015;5:e008031.

252. Howard C, Dupont S. The COPD breathlessness manual': a randomised controlled trial to test a cognitive-behavioural manual versus information booklets on health service use, mood and health status, in patients with chronic obstructive pulmonary disease. NPJ Prim Care Respir Med. 2014;24:14076.

253. Jiang X, He G. Effects of an uncertainty management intervention on uncertainty, anxiety, depression, and quality of life of chronic obstructive pulmonary disease outpatients. Res Nurs Health. 2012;35(4): 409-418.

254. Kapella MC, Herdegen JJ, Perlis ML, et al. Cognitive behavioral therapy for insomnia comorbid with COPD is feasible with preliminary evidence of positive sleep and fatigue effects. Int J Chron Obstruct Pulmon Dis. 2011;6:625-635.

255. Livermore N, Sharpe L, McKenzie D. Prevention of panic attacks and panic disorder in COPD. Eur Respir J. 2010;35:557-563.

256. Lamers F, Jonkers CC, Bosma $\mathrm{H}$, et al. Improving quality of life in depressed COPD patients: effectiveness of a minimal psychological intervention. COPD. 2010;7(5):315-322.

257. Kunik ME, Veazey C, Cully JA, et al. COPD education and cognitive behavioral therapy group treatment for clinically significant symptoms of depression and anxiety in COPD patients; a randomized controlled trial. Psychol Med. 2008;37:1-12.

258. Blumenthal JA, Babyak MA, Keefe FJ, et al. Telephone-based coping skills training for patients awaiting lung transplantation. $J$ Consult Clin Psychol. 2006;74(3):535-544.

259. de Godoy DV, de Godoy RF, Becker Júnior B, et al. The effect of psychotherapy provided as part of a pulmonary rehabilitation program for the treatment of patients with chronic obstructive pulmonary disease. J Bras Pneumol. 2005;31:499-505.

260. de Godoy DV, de Godoy RF. A randomized controlled trial of the effect of psychotherapy on anxiety and depression in chronic obstructive pulmonary disease. Arch Phys Med Rehabil. 2003;84: 1154-1157.

261. Emery CF, Schein RL, Hauck ER, et al. Psychological and cognitive outcomes of a randomized trial of exercise among patients with chronic obstructive pulmonary disease. Health Psychol. 1998;17(3): 232-240.

262. Eiser N, West C, Evans S, et al. Effects of psychotherapy in moderately severe COPD: a pilot study. Eur Respir J. 1997;10:1581-1584.

263. Ramsenthaler C, Siegert RJ, Weatherall M, et al. Cognitive behavioural therapy (CBT) for panic and anxiety in chronic obstructive pulmonary disease - a systematic review. Palliat Med. 2012;26(6):1.
264. Baraniak A, Sheffield D. The efficacy of psychologically based interventions to improve anxiety, depression and quality of life in COPD: a systematic review and meta-analysis. Patient Educ Couns. 2011; 83(1):29-36.

265. Mkacher W, Mekki M, Chaieb F, et al. Balance training in pulmonary rehabilitation: effects on psychosocial outcomes. $J$ Cardiopulm Rehabil Prev. 2015;35(4):278-285.

266. Reychler G, Mottart F2, Boland M, et al. Influence of ambient music on perceived exertion during a pulmonary rehabilitation session: a randomized crossover study. Respir Care. 2015;60(5):711-717.

267. Kaymaz D, Ergün P, Demirci E, et al. Comparison of the effects of neuromuscular electrical stimulation and endurance training in patients with severe chronic obstructive pulmonary disease. Tuberk Toraks. 2015;63(1):1-7.

268. Valenza MC, Valenza-Pena G, Torres-Sanchez I, et al. Effectiveness of controlled breathing techniques on anxiety and depression in hospitalized patients with COPD: a randomized clinical trial. Respir Care. 2014;59(2):209-215.

269. Leung RWM, McKeough ZJ, Peters MJ, et al. Short-form Sunstyle t'ai chi as an exercise training modality in people with COPD Eur Respir J. 2013;41(5):1051-1057.

270. Santana MJ, S-Parrilla J, Mirus J, et al. An assessment of the effects of Iyengar yoga practice on the health-related quality of life of patients with chronic respiratory diseases: a pilot study. Can Respir J. 2013;20(2):e17-e23.

271. Singh VP, Rao V, Prem V, Sahoo RC, Keshav Pai K. Comparison of the effectiveness of music and progressive muscle relaxation for anxiety in COPD - a randomized controlled pilot study. Chron Respir Dis. 2009;6(4):209-216.

272. Bauldoff GS, Hoffman LA, Zullo TG, et al. Exercise maintenance following pulmonary rehabilitation: effect of distractive stimuli. Chest. 2002;122(3):948-954

273. Gift AG, Moore T, Soeken K. Relaxation to reduce dyspnea and anxiety in COPD patients. Nurs Res. 1992;41:242-246.

274. Luk EK, Khan F, Irving L. Maintaining gains following pulmonary rehabilitation. Lung. 2015;193(5):709-715.

275. Sciriha A, Lungaro-Mifsud S, Scerri J, et al. Pulmonary rehabilitation in chronic obstructive pulmonary disease: outcomes in a 12 week programme. Eur J Physiother. 2015;17(4):1-9.

276. Grosbois JM, Gicquello A, Langlois C, et al. Long-term evaluation of home-based pulmonary rehabilitation in patients with COPD. Int J Chron Obstruct Pulmon Dis. 2015;10:2037-2044.

277. da Costa CC, de Azeredo LC, Colombo C, et al. Effect of a Pulmonary Rehabilitation Program on the levels of anxiety and depression and on the quality of life of patients with chronic obstructive pulmonary disease. Rev Port Pneumol. 2014;20(6):299-304.

278. Tselebis A, Bratis D, Pachi A, et al. A pulmonary rehabilitation program reduces levels of anxiety and depression in COPD patients. Multidiscip Respir Med. 2013;8(1):41.

279. Bhandari NJ, Jain T, Marolda C, et al. Comprehensive pulmonary rehabilitation results in clinically meaningful improvements in anxiety and depression in patients with chronic obstructive pulmonary disease. J Cardiopulm Rehabil Prev. 2013;33(2):123-127.

280. Hogg L, Garrod R, Thornton H, et al. Effectiveness, attendance, and completion of an integrated, system-wide pulmonary rehabilitation service for COPD: prospective observational study. COPD. 2012;9(5):546-554.

281. Bentsen SB, Wentzel-Larsen T, Henriksen AH, et al. Anxiety and depression following pulmonary rehabilitation. Scand J Caring Sci. 2013;27(3):541-550.

282. Harrison SL, Greening NJ, Williams JE, et al. Have we underestimated the efficacy of pulmonary rehabilitation in improving mood? Respir Med. 2012;106(6):838-844.

283. Bratås O, Espnes GA, Rannestad T, et al. Relapse of health related quality of life and psychological health in patients with chronic obstructive pulmonary disease 6 months after rehabilitation. Scand J Caring Sci. 2012;26(2):219-227. 
284. von Leupoldt A, Taube K, Lehmann K, et al. The impact of anxiety and depression on outcomes of pulmonary rehabilitation in patients with COPD. Chest. 2011;140(3):730-736.

285. Pirraglia PA, Casserly B, Velasco R, et al. Association of change in depression and anxiety symptoms with functional outcomes in pulmonary rehabilitation patients. J Psychosom Res. 2011;71(1):45-49.

286. Bratås O, Espnes GA, Rannestad T, et al. Pulmonary rehabilitation reduces depression and enhances health-related quality of life in COPD patients - especially in patients with mild or moderate disease. Chron Respir Dis. 2010;7(4):229-237.

287. Spencer LM, Alison JA, McKeough ZJ. Do supervised weekly exercise programs maintain functional exercise capacity and quality of life, twelve months after pulmonary rehabilitation in COPD? BMC Pulm Med. 2007;7:7.

288. Ozdemir EP, Solak O, Fidan F, et al. The effect of water-based pulmonary rehabilitation on anxiety and quality of life in chronic pulmonary obstructive disease patients. Turk Klin J Med Sci. 2010;30(3):880-887.

289. Godoy RF, Teixeira PJ, Becker Júnior B, et al. Long-term repercussions of a pulmonary rehabilitation program on the indices of anxiety, depression, quality of life and physical performance in patients with COPD. J Bras Pneumol. 2009;35(2):129-136.

290. Elçi A, Börekçi S, Ovayolu N, et al. The efficacy and applicability of a pulmonary rehabilitation programme for patients with COPD in a secondary-care community hospital. Respirology. 2008;13(5): 703-707.

291. Kayahan B, Karapolat H, Atýntoprak E, et al. Psychological outcomes of an outpatient pulmonary rehabilitation program in patients with chronic obstructive pulmonary disease. Respir Med. 2006;100(6):1050-1057.
292. Arnardóttir RH, Boman G, Larsson K, et al. Interval training compared with continuous training in patients with COPD. Respir Med. 2007;101(6):1196-204.

293. Goldberg R, Hillberg R, Reinecker L, et al. Evaluation of patients with severe pulmonary disease before and after pulmonary rehabilitation. Disabil Rehabil. 2004;26(11):641-648.

294. Trappenburg JC, Troosters T, Spruit MA, et al. Psychosocial conditions do not affect short-term outcome of multidisciplinary rehabilitation in chronic obstructive pulmonary disease. Arch Phys Med Rehabil. 2005;86(9):1788-1792.

295. Cilione C, Lorenzi C, Dell Orso D, et al. Predictors of change in exercise capacity after comprehensive COPD inpatient rehabilitation. Med Sci Monit. 2002;8(11):CR740-CR745.

296. White RJ, Rudkin ST, Harrison ST, et al. Pulmonary rehabilitation compared with brief advice given for severe chronic obstructive pulmonary disease. J Cardiopulm Rehabil. 2002;22:338-344.

297. Emery CF, Leatherman NE, Burker EJ, et al. Psychological outcomes of a pulmonary rehabilitation program. Chest. 1991;100:613-617.

298. Dekhuijzen PN, Beek MM, Folgering HT, et al. Psychological changes during pulmonary rehabilitation and target-flow inspiratory muscle training in COPD patients with a ventilatory limitation during exercise. Int J Rehabil Res. 1990;13(2):109-117.

299. Wiles L, Cafarella P, Williams MT. Exercise training combined with psychological interventions for people with chronic obstructive pulmonary disease. Respirology. 2015;20(1):46-55.

300. Scottish Intercollegiate Guidelines Network. Critical Appraisal: Notes and Checklists. Secondary Critical Appraisal: Notes and Checklists. 2014. Available from: http://www.sign.ac.uk/methodology/checklists. html. Accessed December 21, 2015.
Neuropsychiatric Disease and Treatment

\section{Publish your work in this journal}

Neuropsychiatric Disease and Treatment is an international, peerreviewed journal of clinical therapeutics and pharmacology focusing on concise rapid reporting of clinical or pre-clinical studies on a range of neuropsychiatric and neurological disorders. This journal is indexed on PubMed Central, the 'PsycINFO' database and CAS,

\section{Dovepress}

and is the official journal of The International Neuropsychiatric Association (INA). The manuscript management system is completely online and includes a very quick and fair peer-review system, which is all easy to use. Visit http://www.dovepress.com/testimonials.php to read real quotes from published authors. 